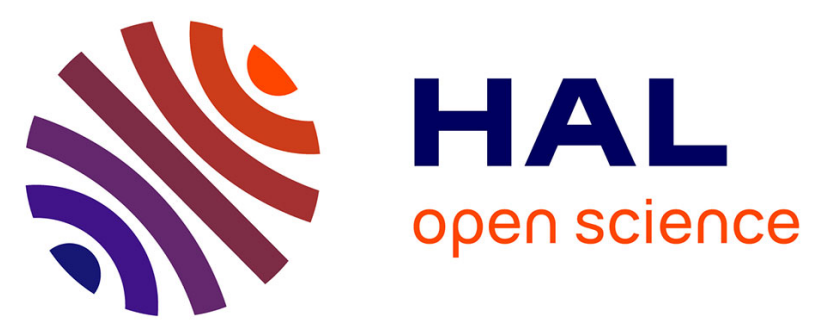

\title{
Human exposure to PCBs, PBDEs and bisphenols revealed by hair analysis: A comparison between two adult female populations in China and France
}

F.-J. Peng, E.M. Hardy, R. Beranger, S. Mezzache, N. Bourokba, P. Bastien, J. Li, C. Zaros, Cécile Chevrier, P. Palazzi, et al.

\section{To cite this version:}

F.-J. Peng, E.M. Hardy, R. Beranger, S. Mezzache, N. Bourokba, et al.. Human exposure to PCBs, PBDEs and bisphenols revealed by hair analysis: A comparison between two adult female populations in China and France. Environmental Pollution, 2020, 267, pp.115425. 10.1016/j.envpol.2020.115425 . hal-02960983

\section{HAL Id: hal-02960983 https://hal.science/hal-02960983}

Submitted on 8 Oct 2020

HAL is a multi-disciplinary open access archive for the deposit and dissemination of scientific research documents, whether they are published or not. The documents may come from teaching and research institutions in France or abroad, or from public or private research centers.
L'archive ouverte pluridisciplinaire HAL, est destinée au dépôt et à la diffusion de documents scientifiques de niveau recherche, publiés ou non, émanant des établissements d'enseignement et de recherche français ou étrangers, des laboratoires publics ou privés. 

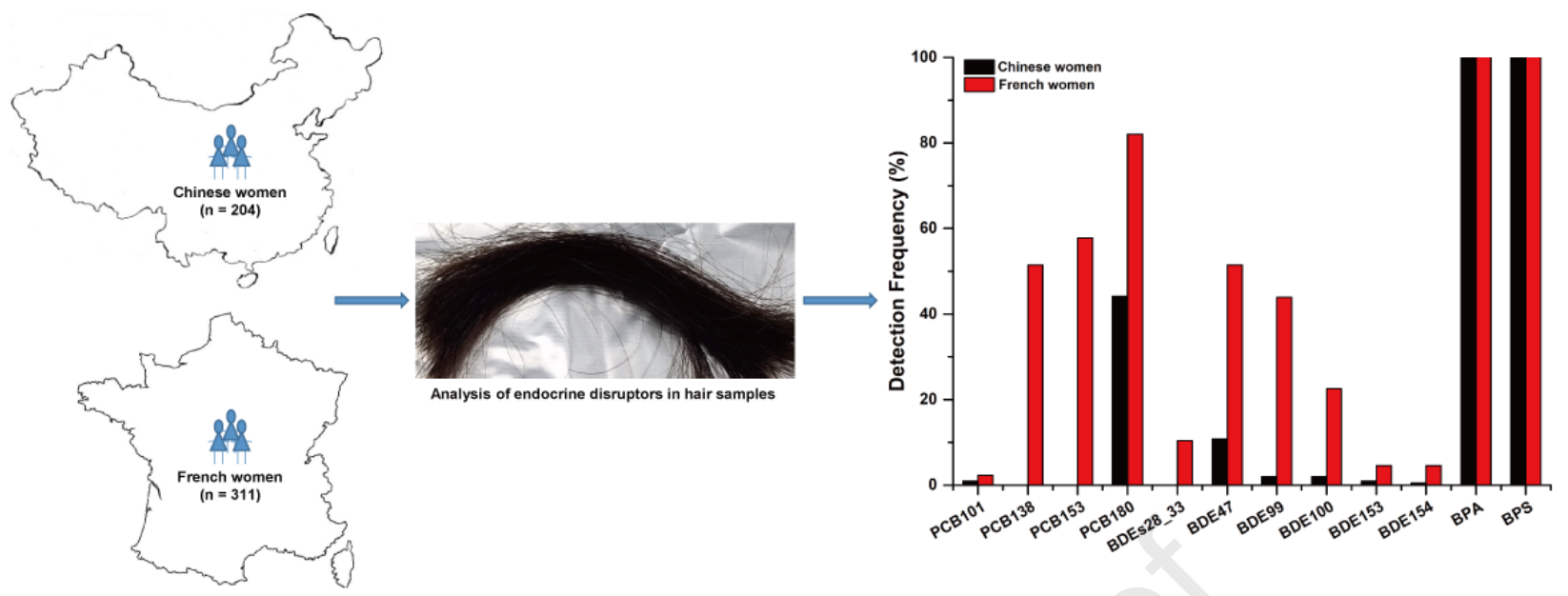
1 Human exposure to PCBs, PBDEs and bisphenols revealed by hair

2 analysis: a comparison between two adult female populations in

3 China and France

4

5 Feng-Jiao Peng ${ }^{\text {a, }}{ }^{*}$, Emilie M. Hardy ${ }^{\text {a }}$, Rémi Béranger ${ }^{\mathrm{b}}$, Sakina Mezzache ${ }^{\mathrm{c}}$, Nasrine

6 Bourokba ${ }^{\mathrm{d}}$, Philippe Bastien ${ }^{\mathrm{c}}$, Jing Li ${ }^{\mathrm{e}}$, Cécile Zaros ${ }^{\mathrm{f},}$ Cécile Chevrier ${ }^{\mathrm{b}}$, Paul

$7 \quad$ Palazzi $^{\text {a }}$, Jeremie Soeur $^{c}$, Brice M.R. Appenzeller ${ }^{\text {a }}$

8

9 a Human Biomonitoring Research Unit, Department of Population Health, 10 Luxembourg Institute of Health, 1 A-B rue Thomas Edison, 1445 Strassen,

11 Luxembourg

$12{ }^{\mathrm{b}}$ Univ Rennes, CHU Rennes, Inserm, EHESP, Irset (Institut de recherche en santé, 13 environnement et travail) - UMR_S 1085, F-35000 Rennes, France

14 c L'Oréal Research and Innovation, 1 avenue Eugène Schueller BP22, 93601

15 Aulnay-sous-Bois, France

$16{ }^{\mathrm{d}}$ L'Oréal Research and Innovation, Biopolis Drive, Synapse, 138623, Singapore

17 e L'Oréal Research and Innovation, No. 550 JinYu Rd., Pudong New Area, China

$18{ }^{\mathrm{f}}$ INSERM, Joint Unit INED-INSERM-EFS, Aubervilliers, France.

$20 *$ Corresponding author.

21 E-mail address: fengjiaopeng@ gmail.com 
22 Abstract: Humans are exposed to various anthropogenic chemicals in daily life, including endocrine-disrupting chemicals (EDCs). However, there are limited data on chronic, low-level exposure to such contaminants among the general population. Here hair analysis was used to investigate the occurrence of four polychlorinated biphenyls (PCBs), seven polybrominated diphenyl ethers (PBDEs) and two bisphenols (BPs) in 204 Chinese women living in the urban areas of Baoding and Dalian and 311 pregnant French women. All the PCBs and PBDEs tested here were more frequently detected in the hair samples of the French women than in those of the Chinese women. In both cohorts, PCB 180 and BDE 47 were the dominant PCB and PBDE congener, respectively. PCB 180 was found in $82 \%$ of the French women and $44 \%$ of the Chinese women, while the corresponding values of BDE 47 were $54 \%$ and $11 \%$, respectively. A discriminant analysis further demonstrated the difference in PCBs and PBDEs exposure profile between the two cohorts. These results demonstrate that hair analysis is sufficiently sensitive to detect exposure to these pollutants and highlight differences in exposure between populations even at environmental levels. Although BPA and BPS were found in $100 \%$ of the hair samples in both cohorts, the French women had significantly higher levels of BPA and BPS than the Chinese women. The median concentrations of BPA were one order of magnitude higher than BPS in both the Chinese (34.9 versus $2.84 \mathrm{pg} / \mathrm{mg}$ ) and the French women (118 versus $8.01 \mathrm{pg} / \mathrm{mg}$ ) respectively. Our results suggest that both French and Chinese populations were extensively exposed to BPA and BPS.

Capsule: In the present study, French women were more frequently exposed to all PCBs and PBDEs analyzed and more extensively exposed to BPA and BPS than Chinese women. 
47 Key words: Human biomonitoring; PCBs; PBDEs; BPs; Hair analysis; Women 48 


\section{Introduction}

Synthetic chemicals have become a part of our daily life. Some of these chemicals are endocrine disrupting chemicals (EDCs) that can interfere with some important developmental processes in humans and wildlife (WHO/UNEP, 2013). Polychlorinated biphenyls (PCBs), polybrominated diphenyl ethers (PBDEs) and bisphenol A (BPA) are ubiquitous endocrine disruptors related to adverse effects on reproduction and development in humans (Rudel and Perovich, 2009; Pinson et al., 2016).

PCBs are a group of industrial compounds formerly used in electrical capacitors, transformers, paint and rubber sealant (Safe, 1984). With regard to their long-range transport capability, persistence, bioaccumulation and toxicity, the production and use of PCBs were globally banned since decades and these chemicals were listed as persistent organic pollutants (POPs) under the Stockholm Convention in 2001 (Xing et al., 2005). PBDEs are another class of POPs, used as flame-retardant additives in a variety of consumer products, e.g. plastics, polyurethane foams, textiles and electronic products (WHO, 1994). PBDEs show similar properties to PCBs, e.g. lipophilic, persistent, and bioaccumulative in biological tissues (Hooper and McDonald, 2000). As a result, the two PBDEs pentabromodiphenyl ether and octabromodiphenyl ether were phased out worldwide between 2004 and 2010 (Gentes et al., 2012). However, they are still frequently detected in human samples, especially in cases of occupational exposure (Hurley et al., 2017; Zota et al., 2018; Qiao et al., 2019). BPA is a high production volume (HPV) chemical used in the synthesis of polycarbonate plastics and epoxy resins (USEPA, 2010). Despite non-persistence, BPA exposure is widespread among general population because of its ubiquity (Meeker and Ferguson, 
74 2011). Considering the endocrine-disruptive property and potential effects on human health of BPA, North America and the European Union have banned its use in certain products, e.g. baby bottles and toys (Chen et al., 2016). As a result, in many consumer products BPA has been replaced by chemicals with similar properties, such as bisphenol S (BPS). However, in vitro and in vivo studies have demonstrated that BPS is as hormonally active as BPA and has also endocrine-disrupting effects (Rochester and Bolden, 2015). Due to the increasing production and usage, BPS has been found in $89.4 \%$ of urine samples $(n=2676)$ from U.S. adults and children participating in the National Health and Nutrition Examination Survey 2013-2014 (Lehmler et al., 2018).

Even though biological fluids have been used extensively for the assessment of human exposure to PCBs, PBDEs (blood) and bisphenols (urine), some studies also demonstrated the possibility to detect these pollutants in hair (Covaci et al., 2008; Barbounis et al., 2012; Behrooz et al., 2012; Wen et al., 2008; Tzatzarakis et a., 2015; Nehring et al., 2017). As compared to other matrices used in biomonitoring (e.g., blood, breast milk, urine or tissues), hair analysis owns several advantages. For instance, hair collection is non-invasive and transport and storage of the samples do not require refrigeration. More importantly, pollutants in hair can be retained for long time intervals, since active processes (metabolism or excretion) within the hair are absent (Tsatsakis et al., 2008). These advantages make hair a biological matrix highly used in legal medicine (Barroso et al., 2011). The concentration of biomarkers in hair is considered to be representative of the chronic exposure of the individual, covering from weeks to months depending on the length of the sample analyzed. The research work conducted over the past decade helped to increasingly consider hair as a suitable 
matrix to monitor human exposure to various pollutants (e.g., Appenzeller et al., 2012; Zheng et al., 2014). In animal models, strong correlation between level of exposure and concentration of chemicals in hair has been demonstrated for many pollutants, particularly for POPs (Appenzeller et al., 2017; Grova et al., 2018). Other studies conducted on human demonstrated that the concentration of PCB and PBDEs in hair was significantly correlated with concentration in blood (Zheng et al., 2014; Zheng et al., 2016) and in tissues (Poon et al., 2014), and could thus be considered a reliable surrogate of the internal dose of pollutants. The previous studies that demonstrated the possibility to detect endocrine disruptors such as PCBs, PBDEs and bisphenols in hair usually focused on a single chemical family. These were mostly conducted on a limited number of subjects selected from the same group (e.g. same living area, occupation), and provided relevant information on local exposures. In order to further explore the relevance of hair analysis in epidemiology, larger studies involving subjects from different geographical areas are still needed to demonstrate the possibility to highlight regional "clusters" of exposure, based on the concentration of pollutants detected in hair.

To assess cumulative exposure to EDCs of female adult populations and to explore the possible regional variability in exposure, the concentration levels of four PCBs, seven PBDEs and two BPs were here determined in hair samples collected from 311 pregnant French women (18-43 years old) belonging to the ELFE cohort and 204 Chinese women (25-45 years old) living in the urban areas of Baoding and Dalian. The specific objectives of the present study were i) to examine exposure profiles of selected EDCs among women in different geographical regions, ii) to compare the exposure patterns between Chinese and French women studied, iii) to investigate 
correlations between the different biomarkers of exposure, and iv) to explore associations between population characteristics and hair concentrations of dominant pollutants.

\section{Materials and methods}

2.1. Chemicals and reagents

Thirteen common EDCs were selected as target compounds in the present study: PCBs 101, 138, 153 and 180, BDEs 28, 33, 47, 99, 100, 153 and 154, BPA and BPS, based on the analytical feasibilities and on their usage, exposure levels in the environment, and results from previous bio-monitoring studies (e.g., Kang et al., 2011; Carnevale et al., 2014; Tzatzarakis et al., 2015). Standards of the four PCBs (i.e., PCBs 101, 138, 153 and 180) and seven BDEs (i.e., BDEs 28, 33, 47, 99, 100, 153 and 154) were purchased from Dr. Ehrenstorfer (Augsburg, Germany) and AccuStandard (New Haven, CT, USA), respectively. BPA and BPS were obtained from Sigma-Aldrich (Diegem, Belgium). Abbreviations and other details (e.g., CAS no. and Log Kow) are provided in the supporting information (Table S1). Internal standards gamma-hexachlorocyclohexane- $\mathrm{d}_{6} \quad\left(\gamma-\mathrm{HCH}-\mathrm{d}_{6}\right), \quad \beta$-endosulfan- $\mathrm{d}_{4}$ and trans-permethrin- $\mathrm{d}_{6}$ were purchased from Dr. Ehrenstorfer (Germany); BPA- $\mathrm{d}_{16}$ from Sigma-Aldrich (Belgium) and thiabendazole $-{ }^{13} \mathrm{C}_{6}$ from TRC (Canada). The purity of each standard was higher than $95 \%$. Methanol (analytical grade), acetonitrile (HPLC grade), ethyl acetate (pesticide grade), formic acid (HPLC grade) and ammonium acetate (HPLC grade) were acquired from Biosolve (Germany). Sodium phosphate monobasic monohydrate $\left(\mathrm{NaH}_{2} \mathrm{PO}_{4}, \mathrm{H}_{2} \mathrm{O}\right)$, sodium dodecyl sulfate (SDS), sodium metabisulfite $\left(\mathrm{Na}_{2} \mathrm{~S}_{2} \mathrm{O}_{5}\right)$ and 2, 3, 4, 5, 6-pentafluorobenzyl bromide (PFBBr) were purchased from Sigma-Aldrich (Diegem, Belgium). Potassium carbonate $\left(\mathrm{K}_{2} \mathrm{CO}_{3}\right)$, 
sodium hydroxide $(\mathrm{NaOH})$ and sodium phosphate dibasic dihydrate $\left(\mathrm{Na}_{2} \mathrm{HPO}_{4}, 2 \mathrm{H}_{2} \mathrm{O}\right)$ were bought from Merk (Germany).

\subsection{Sample collection}

Hair samples were collected from 204 Chinese women in 2016 and 311 pregnant French women in 2011. The selection of these two populations was based on the difference in historical consumption of PCBs and penta-BDEs between China and France and on the difference in estimated BPA daily intake between Chinese adults and French adults (e.g., Breivik et al., 2002; Mai et al., 2005; Huang et al., 2017; Abbasi et al., 2019). Details on the study design, populations, recruitment, and sampling procedures have been previously reported (Béranger et al., 2018; Palazzi et al., 2018; Charles et al., 2019; Peng et al., 2020). In summary, the Chinese women were recruited in the framework of a clinical study investigating the effect of chronic pollution exposure on skin, scalp and hair (Naudin et al., 2019). Inclusion criteria for selection of Chinese women were: presenting natural hair from root to tip and a length of hair $\geq 30 \mathrm{~cm}$, non-smoking, non-drinking alcohol, healthy, not being pregnant, age between 25 and 45 years, and living in the cities of Baoding and Dalian (Northern China) for at least 15 years with an indoor occupation (Palazzi et al., 2018). Socio-demographic data (age and education) and frequency of consuming red meat or fish/seafood were collected through self-reported questionnaires (Table S2). The pregnant French women were selected from the ELFE cohort designed to evaluate the influence of environment on child development, health and socialization (Charles et al., 2019). Selected pregnant French women in the current study met the following inclusion criteria: presenting a sufficient amount of hair for analysis, giving birth to singleton infants without congenital malformation, age over 18 years, and resident in 
174 either northeastern (Champagne-Ardenne, Bourgogne, and Lorraine) or southwestern 175 (Aquitaine, Midi-Pyrénées, and Poitou-Charentes) French regions (Béranger et al., 176 2018). Most of these French women were office, sales, and service workers $(52.7 \%)$ 177 or involved in intermediate occupations $(25.1 \%)$. Self-reported questionnaires were 178 administered to collect information on sociodemographic (e.g., age and education; 179 Table S2) and medical characteristics during the maternity stay (before discharge). 180 For both Chinese women and French women, height and weight were measured to 181 calculate body mass index (BMI). Hair samples were collected from the scalp in the 182 posterior vertex region of the head. Each hair sample ( 100 fibers $)$ was wrapped in 183 aluminum foil, sealed in a kraft envelope and stored at room temperature. All the participants signed an informed consent. The protocol of the Chinese women study was approved by the Ethics Committee of the Chinese Academy of Inspection and Quarantine Cosmetics Tech Center (protocol n: 2015-033-DY-024), and the protocol of French women study was approved by the French Consulting Committee for the Treatment of Information in Medical Research ( $\left.\mathrm{n}^{\circ} 10.623\right)$, the French National Commission for the Confidentiality of Computerized Data $\left(\mathrm{n}^{\circ} 910504\right)$, and the Committee for the Protection of Persons ( ${ }^{\circ}$ CPP-IDF IX-11024).

\subsection{Sample preparation and analysis}

193 For the Chinese women, only the $0-12 \mathrm{~cm}$ (proximal part $=$ starting from the skin) of 194 hair strands were used for analyses, which corresponds to the 12 months before hair sampling (Kintz et al., 2015). For the French women, only the 0-9 cm (proximal part) of hair strand was used for analysis, which covers the period of pregnancy by assuming an average hair growth rate of $1 \mathrm{~cm}$ per month (Béranger et al., 2018). Hair samples were successively washed with a sodium dodecyl sulfate solution and 
199 methanol before extraction, to remove any possible externally deposited chemicals on

200 the hair surface, according to a protocol previously developed (Duca et al., 2014).

201 Hair samples were then powdered using a Retsch-MM 200 vibrant-ball mill (5 min at $20225 \mathrm{~Hz})$.

203

204

205

206

207

The protocol for the analysis of target EDCs in hair was the same as that reported for pesticides in hair (Hardy et al., 2015; Béranger et al., 2018). Briefly, EDCs were extracted from approximately $50 \mathrm{mg}$ of hair powder using $1 \mathrm{~mL}$ of acetonitrile/water mixture (80/20, v/v) incubated overnight at $40{ }^{\circ} \mathrm{C}$. An aliquot of $0.3 \mathrm{~mL}$ was used to analyze PCBs 101, 138, 153, BDEs 28 and 33 by solid phase microextraction (SPME) analysis coupled to gas chromatography-tandem mass spectrometry (GC-MS/MS). Another aliquot of $0.3 \mathrm{~mL}$ was used to analyze PCB 180, BDEs 47, 99, 100, 153, 154 and BPA by derivatization with $30 \mathrm{mg}$ of $\mathrm{K}_{2} \mathrm{CO}_{3}, 1 \mathrm{~mL}$ of acetonitrile and $100 \mu \mathrm{L}$ of PFBBr-acetonitrile mixture (75/25, v/v) and analysis by GC-MS/MS; a final portion of $0.2 \mathrm{~mL}$ was used to analyze BPS by ultra-performance liquid chromatography-tandem mass spectrometry (UPLCMS/MS).

Procedure blanks and quality control (QC) samples were determined per set of 30 samples. QC samples were a pool of hair spiked with standards at eight different concentrations $(0.5,1,2,5,10,20,50$ and $100 \mathrm{pg} / \mathrm{mg})$. They were analyzed simultaneously and in the same way as field samples. The recoveries of each compound at concentrations of 1,10 and $100 \mathrm{pg} / \mathrm{mg}$ ranged $64 \%-141 \%$. Limit of detection (LOD) was defined as the lowest concentration of a compound detected in the samples analyzed in the current study, as previously detailed (Appenzeller et al., 2017). LODs ranged from $0.02 \mathrm{pg} / \mathrm{mg}$ for PCB 180 to $5.47 \mathrm{pg} / \mathrm{mg}$ for BPA. Because 
of the co-elution, BDE 28 and BDE 33 could not be differentiated and were marked as BDE 28_33. Method validation parameters are presented in Table S3.

\subsection{Statistical analysis}

Statistical analyses were performed in $\mathrm{R}$ program version 3.5.2. Statistical significance was defined at a $p$ value $<0.05$. For descriptive statistics, if the percentile estimate was below LOD, the value was reported as “< LOD”. In further statistical analyses, concentrations below the LOD were assigned a value of LOD/2. Mann-Whitney U tests were performed to compare concentrations of each compound between the two countries or between the two sub-regions within a country. Kruskal-Wallis tests were conducted to compare concentrations of dominant compounds (detection frequency (DF) $\geq 75 \%$ ) among the four sub-regions. Wilcoxon signed rank tests were performed to examine the difference in concentrations between chemicals. Partial least square-discriminant analyses (PLS-DA) were conducted on POPs profile data using the mixOmics R package (Rohart et al., 2017), to estimate discrimination between Chinese and French hair samples. Spearman rank correlation coefficients (r) between compounds were calculated for each data set (China and France separately). Only chemicals detected in more than ten samples were included in the correlation analyses, and the results were presented in a heatmap. Multivariate linear regression analyses were conducted on each data set (China and France separately) to evaluate associations of hair concentrations of dominant chemicals (DF $\geq 75 \%$ ) with population characteristics (Table S2). In these models, response variables were concentrations of dominant pesticides while explanatory variables were population characteristics. For the Chinese women, the specific population characteristics were age, BMI, education, living cities (Baoding and Dalian), and 
249 frequency of consuming red meat or fish/seafood, which were reported in our 250 previous studies (Palazzi et al., 2018; Peng et al., 2020). For the French women, the 251 specific population characteristics were age, BMI, education, living areas (northeast 252 and southwest), and smoking habit (smoking and non-smoking), which were partly 253 reported in previous studies (Béranger et al., 2018; 2020). Age and BMI were 254 considered as continuous variables, and the remaining characteristics were considered 255 as categorical variables (Table S2). Concentration data were $\log 10$ transformed in 256 these analyses as their distributions were highly skewed. Backward stepwise 257 elimination was used to identify optimal models (Zuur et al., 2009). Residuals were 258 visually inspected for heterogeneity and independence by plotting residuals against 259 fitted values and each explanatory variable, respectively. Additionally, a histogram of 260 the residuals was used to verify normality.

\section{Results}

\subsection{Hair concentrations of EDCs}

\subsubsection{Chinese women}

Table 1 presents the descriptive results of all the compounds measured in this study.

Of the four PCB congeners, PCB 180 was the most frequently detected (DF $=44 \%$;

Fig. 1); PCB 138 and 153 were not detected in any samples; PCB101 was found in two hair samples from women in Dalian (Table S4). All the seven PBDEs were seldom detected (Fig. 1). BDE 47 was the predominant congener and detected in $11 \%$ of the hair samples. The median concentrations of all PCB and BDE congeners were below the LODs. BPA and BPS were detected at measurable concentrations in all the

272 hair samples. The $25^{\text {th }}, 50^{\text {th }}$ and $75^{\text {th }}$ percentile concentrations of BPA were $23.4,34.9$ 273 and $57.2 \mathrm{pg} / \mathrm{mg}$, respectively, and the corresponding levels of BPS were 1.43, 2.84 
and $6.34 \mathrm{pg} / \mathrm{mg}$, respectively. The BPA concentration was significantly higher than BPS (Wilcoxon signed rank test, $p<0.05$ ). Comparing women in Baoding with those in Dalian, concentrations of PCB 180 and BPA were significantly higher in hair samples from the women in Baoding, but the BPS concentration was significantly higher in hair samples from the women in Dalian (Mann-Whitney U tests; Table S4). Given the low DFs of most PCBs and BDEs, only PCB 180, BDE 47, BPA and BPS were included in the correlation analysis. There was a statistically significant positive correlation between the concentration levels of BPA and BPS $(\mathrm{r}=0.31 ; p<0.001)$.

\subsubsection{French women}

Similar to the Chinese women, PCB 180 was the most frequently detected PCB congener in the French women, with DF of $82 \%$ and a median concentration of 0.25 pg/mg. While PCB 101 was detected in only 2\% of the hair samples, PCB 138 and PCB 153 were detected in 45 and $49 \%$ of the hair samples, respectively. Again, BDE $47(\mathrm{DF}=57 \%)$ was more frequently detected than the remaining six BDE congeners (Fig. 1), with concentrations ranging from <LOD to152 $\mathrm{pg} / \mathrm{mg}$ and a median concentration of $1.37 \mathrm{pg} / \mathrm{mg}$. BDE 99 and 100 were detected in 49 and $20 \%$ of the hair samples, with concentrations in the ranges of <LOD-396 and <LOD-73.7 pg/mg, respectively. BDEs 28_33, 153 and 154 were detected at similar frequencies (DF $=7$, 5 and $4 \%$, respectively). BPA and BPS were detected in $100 \%$ of hair samples, but the concentration of BPA was significantly higher than BPS (Wilcoxon signed rank test, $p<0.05)$. The $25^{\text {th }}, 50^{\text {th }}$ and $75^{\text {th }}$ percentile concentrations of BPA were $63.4,118$ and $213 \mathrm{pg} / \mathrm{mg}$, respectively, and the corresponding levels of BPS were 2.11, 8.32 and $27.9 \mathrm{pg} / \mathrm{mg}$, respectively. Comparing pregnant women in northeastern France with those in southwestern France, the concentrations of BDEs 28_33, 100, 153 and 154 
299

300

301

302

303

304

305

306

307

308

309

310

311

312

were significantly higher in the hair samples collected from women in southwestern France ( $p \leq 0.015$; Table S4). There were no statistically significant differences in concentrations of the remaining compounds between the two regions.

Because PCB 101 was found in only $2 \%$ of the hair samples, it was excluded from the correlation analysis. Within the remaining three PCB congeners, there was a strong positive correlation between PCBs 138 and $153(\mathrm{r}=0.80, p<0.001)$. These two congeners were significantly positively correlated with PCB 180 as well (Fig. 2), with correlation coefficient values of 0.33 and 0.35 , respectively. Of PBDEs, the strongest correlation was found between BDEs 153 and $154(r=0.65, p<0.001)$, followed by correlations between BDEs 99 and $100(\mathrm{r}=0.53, p<0.001)$, between BDEs 99 and $47(\mathrm{r}=0.49, p<0.001)$, between BDEs 100 and $153(\mathrm{r}=0.44, p<0.001)$, and between BDEs 100 and $47(\mathrm{r}=0.43, p<0.001)$ (Fig. 2). BPA and BPS were strongly positively correlated $(\mathrm{r}=0.67, p<0.001)$. Additionally, there were weaker but statistically significant correlations between compounds from different classes (Fig. 2). For example, BPA and BPS were significantly correlated with PCB 180, BDEs 47, 99 and $100(\mathrm{r}=0.14-0.36, p \leq 0.014)$.

\subsection{Comparing EDCs in Chinese women and French women}

All the target PCBs and PBDEs were more frequently detected in the French women $(\mathrm{DFs}=2-82 \%)$ than in the Chinese women $(\mathrm{DFs}=0 \%-44 \%$; Fig. 1). French women had significantly higher levels of all PCBs and PBDEs than Chinese women (Mann-Whitney U tests, $p \leq 0.017$; Table 1), except PCB 101 that was seldom found in both populations. The PLS-DA plot illustrates the discrimination between Chinese and French women on the basis of their PCBs and PBDEs concentration in hair (Fig. 
3a). Additionally, hair samples from the women in northeastern France were separated from those in southeastern France, but there was no clear separation between samples from the Chinese women in Baoding and Dalian (Fig. 3b).

Although BPA and BPS were found in all the hair samples from both cohorts, the French women had significantly higher levels of BPA and BPS than the Chinese women (Fig. 4). Concentrations of BPA and BPS in French women from both sub-regions (northeast and southwest) were significantly higher than those from the two Chinese cities (Kruskal-Wallis tests, $p<0.05$, Fig. S1).

3.3. Associations between population characteristics and hair concentrations of dominant EDCs

Results from the Multivariate linear regression are presented in Table S5. Chinese women consuming red meat 4-7 times/week had 93\% (95\% confidence interval (CI): 22 to $205 \%$ ) higher level of BPA in hair compared to those never consuming red meat or less than 1 time/week. Women living in Dalian had 62\% (95\% CI: 0.7 to 121\%) higher BPS level compared to those in Baoding. Age, BMI, education, and frequency of fish/seafood consumption were not statistically significantly associated with either BPA or BPS level in hair.

Regarding the French women, the PCB 180 concentration in hair was positively associated with age of the women $(p=0.045)$ but negatively associated with the education levels $(p=0.006)$. A one-year increase in age was related to $3.6 \%$ (95\% CI:

0 to $7.2 \%$ ) increase in PCB 180 level. Women with university-level education had $38 \%$ (95\% CI: -56 to $-13 \%$ ) lower PCB level in hair compared to those with lower 
349 education levels. BPA concentration was also negatively associated with the

350 education levels (both $p<0.001$ ). Women who reported university-level education

351 had $28 \%$ (95\% CI: -40 to $-13 \%$ ) lower BPA level than those who reported lower

352 education levels. Additionally, a one-unit increase in BMI was associated with $3.6 \%$

353 (95\% CI: 1.6 to $5.7 \%$ ) increase in BPA level. The BPS concentration was also 354 positively associated with BMI $(p=0.036)$. A one-unit increase in BMI was 355 associated with $4.9 \%$ (95\% CI: 0.2 to 9.6\%) increase in BPS level. In addition, 356 smoking women had $74 \%$ (95\% CI: 8.9 to $177 \%$ ) higher BPS level compared to 357 non-smoking women. There were no statistically significant associations between the 358 living areas and concentrations of the above three compounds.

359

360

361

\section{Discussion}

We reported hair concentrations of four PCBs, seven PBDEs, and two BPs in 204 Chinese and 311 French women. We found higher detection frequencies (DF) and concentrations for all the target PCBs and PBDEs in the French women as compared to the Chinese women (Fig. 1 and Table 1). The discriminant analysis further demonstrated the difference in the PCBs and PBDEs exposure profile between the two populations (Fig. 3). Notably, PCB 180 was detected in $82 \%$ of the French women, suggesting the widespread exposure to PCB 180 in this population. Additionally, the DF values of PCBs 138, 153 and 180 determined in the French women $(45,50$, and $82 \%$, respectively) are greater than those $(23 \%, 25 \%$ and $59 \%)$ reported from a recent study conducted on 151 French children using hair analysis (Iglesias-González et al., 2020). The children studied by the latter authors and the women described in the present study were not necessarily living in the same places, but both studies included a large number of subjects and covered several areas of 
374 France. Although the comparison between the two populations has to be conducted

375 with caution, the higher DF observed in the women compared to the children could

376 suggest lifelong bioaccumulation of PCBs in the French women. BPA and BPS were

377 detected in $100 \%$ of the hair samples from both the Chinese and the French women,

378 but the Chinese women had significantly lower concentrations of both BPA and BPS

379 than the French women (Fig. 4). These results suggest that both cohorts were widely

380 exposed to BPA and BPS. These results also confirm that hair analysis can effectively

381 distinguish different exposure patterns of organic contaminants among general 382 populations.

383

The higher DF and concentration of PCBs in the French women is likely due to the higher use of PCBs in France than in China in the past, as it has been reported that France and China contributed to approximately $4.1 \%$ and $0.6 \%$ of the total historical global PCB consumption, respectively (Breivik et al., 2002). Although the sampling time was slightly different between the French and the Chinese women (2011 versus 2016), this time difference is unlikely to be responsible for the differences reported here because of the well-known low degradation of PCBs in the environment. Similarly, the different life stages (pregnancy vs non-pregnancy) between the French and the Chinese women is not considered to have biased the comparison between the two cohorts. This assumption is supported by a previous work conducted on the same French women, which demonstrated that the concentration of pesticides (both persistent and non-persistent) in hair present very low variability between the different trimester of pregnancy (Béranger et al., 2018). Similarly, Adetona et al. (2013) reported that the concentration of PCBs in plasma was relatively stable across trimesters, suggesting that pregnancy would have a limited influence on circulating 
399 PCBs. The high frequency of PCB detection in the French women observed here is in

400 line with a previous study in which all the four PCBs were detected in $100 \%$ of breast

401 milk samples collected from French women between 2011 and 2014 (Antignac et al.,

402 2016). Of the four PCB congeners, PCB 180 was the predominant congener in both

403 Chinese women and French women (Fig. 1 and Table 1), even though PCB 180 was

404 much less consumed than the remaining three congeners in both countries (Breivik et

405 al., 2002). Likewise, PCB 180 was the most abundant congener of these four PCBs

406 (PCB 101, 138, 153, and 180) in the hair samples collected from Iranian pregnant

407 women (Behrooz et al., 2012) and French Children (Iglesias-González et al., 2020).

408 However, in hair samples from Romanian adolescents, PCB 153 was more frequently

409 detected and more abundant than PCB 180 (Covaci et al., 2008). These results likely

410 reflect the difference in historical use of commercial PCB products between countries.

411 Here the frequent detection of PCB 180 in the two female populations probably

412 suggests ongoing exposure to $\mathrm{PCBs}$ because of their lipophilic properties and

413 persistence in the environment, even though their production and usage have been

414 restricted or banned in China and France since the 1980s (Xing et al., 2005; Arnich et

415 al., 2009). The ongoing exposure of the French women is supported by the fact that

416 PCBs were still detected in hair samples collected in 2014-2015 from French children

417 aged from 1 to 12 years old, suggesting that exposure was still present in France

418 recently (Iglesias-González et al., 2020). However, the contribution of past exposure

419 to the body burden of PCBs revealed by hair analysis cannot be discounted, as PCBs

420 are persistent in the human body as well, with estimated intrinsic elimination

421 half-lives at background levels of 10.8, 14.4 and 11.5 years for PCBs 138, 153 and

422 180, respectively (Ritter et al., 2011). Additionally, because PCB 180 was much less

423 consumed than the remaining three congeners in both countries (Breivik et al., 2002), 
the higher presence of PCB 180 could also suggest higher potential to transfer and/or accumulate in human than lower chlorinated PCBs, as suggested by Norström et al. (2010). Compared with previously reported data on general populations (Table S6), median concentrations of all PCBs determined here were lower than those reported for Philippine pregnant women (Malarvannan et al., 2013) and Romanian adolescents (Covaci et al., 2008). Our populations also had lower levels of PCBs 138 and 180 than Iranian women (Behrooz et al., 2012), and lower levels of PCBs 101, 138 and 153 than Chinese adults living in Zhejiang Province (Zhao et al., 2008). However, the interpretation of these comparisons should be careful, as the sample size was very small in the studies mentioned above $(\mathrm{n}=4-42$; Table S6) and different analytical methods were applied between studies.

Similar to PCBs, higher frequencies of detection and higher levels of all PBDEs were observed in the French women than in the Chinese women. Again, this may reflect their greater consumption in France than in China in the past, since commercial penta-BDE and octa-BDE have been phased out in the European Union since 2004 and in China since 2009 (La Guardia et al., 2006; Chen et al., 2018). This hypothesis is further supported by the fact that deca-BDE was the predominant BDEs produced and used in China (Mai et al., 2005). In both female populations, tetra- (BDE 47) and penta-BDEs (BDEs 99 and 100) were more frequently detected than tri- (BDEs 28_33) and hexa-BDEs (BDEs 153 and 154). This is most likely related to the penta-BDE technical formulation, as BDEs 47, 99 and 100 were the major constituents of commercial penta-BDE mixtures (La Guardia et al., 2006). Although the content of BDE 99 was slightly higher than BDE 47 in penta-BDE products (DE-71 and Bromkal 70-5DE; La Guardia et al., 2006), BDE 47 was the predominant congener in 
449 both female populations (Table 1). This could be explained by differences in 450 assimilation efficiencies between BDE 47 and 99, by debromination of higher 451 brominated congeners (e.g., BDE 99 and 209), or by their combinations, as reported 452 by Stapleton et al. (2004). For instance, debromination of BDE 99 to BDE 47 has 453 been demonstrated in the gut of common carp (Cyprinus carpio) (Stapleton et al., 454 2004). Similar results have been reported for hair samples from Canadian women in 455 Ontario (Carnevale et al., 2014) and Chinese adults in Pearl River Delta (Kang et al., 456 2011) and serum samples from American pregnant women (Kalloo et al., 2018). 457 However, in hair samples from Spanish, Canadian and French children, BDE 99 was 458 more predominant than BDE 47 (Tadeo et al., 2009; Aleksa et al., 2012; 459 Iglesias-González et al., 2020). This difference may result from the difference in 460 exposure routes in children (diet versus dust), difference in use of specific BDE 461 commercial products, or differences in bioaccumulation depending on the congener.

462 In comparison with existing data on general populations in the literature $(n=4-65$;

463 Table S6), concentrations of all the BDEs in our study populations were lower than 464 those in Canadian adults (Poon et al., 2014), Philippine pregnant women 465 (Malarvannan et al., 2013), and American adults (Liu et al., 2016). The median 466 concentration of BDE 47 in our French women was comparable to that reported for 467 reference adults in Zhejiang Province (1.17 pg/mg; Zhao et al., 2008), but was higher 468 than those reported for the Spanish (0.51 and $0.60 \mathrm{pg} / \mathrm{mg}$; Tadeo et al., 2009), Polish 469 adults (0.40 pg/mg; Król et al., 2014), Canadian children (0.31 pg/mg; Aleksa et al., 470 2012) and Chinese in Guangdong Province (0.33 and 0.42 pg/mg; Zheng et al., 2011) 471 and Shanghai (0.12 and $0.34 \mathrm{pg} / \mathrm{mg}$; Tang et al., 2013). These differences suggest 472 differences in the body burden of BDEs, which is due to bioaccumulation over time 
and/or to current exposure, although the influence of the analytic methods cannot be excluded.

Numerous studies demonstrated the ubiquitous exposure of the general population to BPA and BPS based on analyses on blood and urine (e.g., Larsson et al., 2017; Jin et al., 2018; Lehmler et al., 2018; Owczarek et al., 2018). Likewise, these bisphenols were detected in all the hair samples from both the Chinese and the French women involved in the present study, indicating the widespread exposure to BPA and BPS in these two populations. The higher exposure of the French women indicated by higher hair levels of bisphenols than the Chinese women (Fig. 4) is in line with the greater estimated BPA daily intake in French adults $(\sim 56.0 \mathrm{ng} / \mathrm{kg}$ bw/day) than in Chinese adults ( 33.3 ng/kg bw/day) (Huang et al., 2017). The significantly higher concentration of BPA relative to BPS in both female populations suggests higher exposure to BPA than BPS. Likewise, the BPA level was found to be higher than BPS in plasma samples collected from Chinese adults (mean concentration: 0.40 versus $0.15 \mathrm{ng} / \mathrm{mL}$; Jin et al., 2018) and in urine samples from American adults participating in the National Health and Nutrition Examination Survey (NHANES) 2013-2014 (median concentration: 1.24 versus $0.37 \mathrm{ng} / \mathrm{mL}$; Lehmler et al., 2018). Additionally, BPA (Log Kow=3.32; Chen et al., 2016) is more lipophilic than BPS (Log Kow=1.65; Michałowicz et al., 2014), which could increase BPA accumulation in human body relative to BPS. Comparing BPA determined here with previously reported data on general populations (Table S6), the median concentrations of BPA in our study populations were higher than those reported in Greek adults $(27.7$ and $13.8 \mathrm{pg} / \mathrm{mg}$; Tzatzarakis et al., 2015; Karzi et al., 2018), Greek children (12.4 pg/mg; Karzi et al., 2018), Spanish adults (4.60 pg/mg; Rodríguez-Gómez et al., 2017), and Korean adults 
498 (<22.9 pg/mg; Lee et al., 2017) but lower than that reported in Polish adults $(337.5$

$499 \mathrm{pg} / \mathrm{mg}$; Nehring et al., 2017). However, the small sample size $(\mathrm{n}=6-72)$ in the studies

500 above may also explain the differences between them. Unlike BPA, there are no data

501 on BPS occurrence in human hair. Therefore, the present study is the first one to

502 report BPS concentrations in human hair.

503

504 We found stronger correlations between chemicals belonging to the same chemical

505 class than between chemicals from different classes, which is in line with previous

506 findings that chemicals with similar structures were more strongly correlated

507 compared to unrelated chemicals (Kalloo et al., 2018; Béranger et al. 2018; Peng et al.,

508 2020). Among the French women, we found strong correlations between PCBs 138

509 and $153(r=0.80)$, between BDEs 47, 99 and $100(r=0.43-0.53)$, between BDEs 153

510 and $154(\mathrm{r}=0.65)$, as well as between BPA and BPS $(r=0.67)$ (Fig. 2). This is most

511 likely related to their combined use in industrial and commercial products and similar

512 exposure source (e.g., food products). For example, PCBs and PBDEs that have been

513 classified as POPs were sold as commercial mixtures, e.g. Aroclor 1254, Aroclor

514 1260, DE-71 and Bromkal 70-5DE (Breivik et al., 2002; La Guardia et al., 2006).

515 Likewise, in serum samples from American pregnant women, BDE 47 was strongly

516 correlated with BDE $99(\mathrm{r}=0.9)$ and BDE $100(\mathrm{r}=0.9)$ (Kalloo et al., 2018).

517 However, the correlation between BPA and BPS in Chinese women was much weaker

518 than that in the French women $(r=0.31$ versus 0.67$)$. This discrepancy may be related

519 to the difference in the use of specific products containing BPA and BPS, since BPA

520 and BPS have been found in foodstuffs (e.g., dairy products and meat) from the

521 United States (Liao and Kannan, 2013) and in personal care products from China and

522 the United States (Liao and Kannan, 2014). We did not find any hypothesis 
523 explaining why BPA and BPS were weakly (although statistically significantly)

524 correlated with PCB 180, BDEs 47, 99 and 100 (Fig. 2).

525

The hair concentrations of the three dominant pollutants (PCB 180, BPA and BPS) were found to be significantly associated with several population characteristics (Table S5). PCB 180 concentration increased with the age of French women, despite the narrow age range (18-44 years). A similar association has been reported in serum samples from a Romanian population (age: 8-90 years; Dirtu et al., 2006). These findings may indicate the lifetime cumulative exposure to PCBs among general populations. The significant positive association between BPA concentrations in the Chinese women's hair and frequency of consuming red meat may suggest that red meat could be a source of exposure to BPA in China, as it has been reported that BPA was detected in $76.5 \%$ of meat and meat products from the United States (Liao and Kannan 2013). Although fish/seafood has been recognized as a dietary source of exposure to BPA in addition to red meat (Liao and Kannan, 2013), there was no significant association between frequency of consuming fish/seafood and hair BPA concentration. However, we were not able to confirm such relations in the French women, as there were no data on consumption of red meat or fish/ seafood for this population. Unlike in Chinese women, BMI and education were found to be significantly associated with hair BPA level in the French women. Likewise, previous studies also reported discordant results concerning the relationship between BPA level and BMI (Carwile and Michels, 2011; Arbuckle et al., 2014). Therefore, these results should be interpreted cautiously. In agreement with our results, a negative relation was observed between education and BPA level in urine samples collected from women in a Canadian pregnancy cohort study (Arbuckle et al., 2014). Similar to BPA, 
548 hair BPS concentration was associated with different characteristics between the

549 Chinese (living cities) and French women (BMI and smoking habit). The relation

550 between living cities and BPS level in the Chinese women may be caused by

551 difference in food contamination, as it has been suggested that diet is the most

552 important source of exposure to bisphenols in the general population (Wang et al.,

553 2015). The positive association between BMI and hair BPS concentration in the

554 French women is in line with the findings of Liu et al. (2017), who reported that

555 adults who were obese had higher urinary BPS level than adults who were not obese

556 in the National Health and Nutrition Examination Survey (NHANES) of the US

557 population.

558

559 Our study is subjected to a limitation. The analysis of PBDEs was restricted to

560 penta-BDEs in the present study, based on the results from most of previous

561 biomonitoring studies. However, deca-BDE (BDE-209) has also been detected in

562 non-occupationally exposed humans (e.g., breast milk and blood), although

563 bioaccumulation of BDE-209 was assumed to be low because of its large molecular

564 size, extreme hydrophobicity and low bioavailability (Frederiksen et al., 2009; Van

565 den Berg et al., 2017). Despite this limitation, our study aims, to show cumulative

566 exposure to EDCs in female adult populations and to identify potential regional

567 variability in exposure, are accomplished. Additionally, our study has several

568 strengths. The large sample size enables us to identify potential differences in

569 biomarkers concentrations between populations. Measurements were done in the same

570 laboratory and therefore our comparisons between the two cohorts are not impacted

571 by differences in analytical techniques. To our knowledge, this is the first study

572 reporting BPS concentrations in human hair. 


\section{Conclusions}

575 The present study demonstrate that hair analysis is sufficiently sensitive to detect 576 exposure to endocrine disruptors such as PCBs, PBDEs and bisphenols, and highlight 577 differences in exposure between populations even at environmental levels. The body 578 burden of target PCBs and PBDEs determined by hair analysis was different between 579 the Chinese and the French women studied, indicating that the two cohorts had 580 different PCBs and PBDEs exposure profile. Although the French women were more 581 extensively exposed to BPA and BPS compared to the Chinese women, these two 582 contaminants were detected in all the hair samples from both cohorts, suggesting the 583 widespread exposure to BPA and BPS in general populations. Our results demonstrate 584 the multiple exposure of the general population and provide baseline data on women's exposure to target EDCs.

587 Acknowledgements

588 ELFE is a study conducted conjointly by National Institute of Demographic Studies 589 (Ined), French National Institute for Health and Medical Research (Inserm), French 590 blood establishment (EFS), French Institute for Public Health Surveillance (InVS),

591 French National Institute for Statistics and Economic Studies (Insee), General 592 Directorate for Health (DGS, Ministry of Health), General Directorate for Risk 593 Prevention (DGPR, Ministry of Environment), Directorate for Research, Studies, 594 Evaluation and Statistics (Drees) and French National Family Allowance Fund (Cnaf). 595 It receives additional funding from the Ministry of Research, Committee on the 596 human and social sciences (CCDSHS), and the Ministry of Culture and 
597 Communication (Deps). As part of the RECONAI platform, Elfe also receives

598 funding from the National research agency (ANR-11-EQPX-0038).

599 The author would like to acknowledge the financial support of L'Oréal for the hair 600 analysis performed on the Chinese women.

601

602

\section{References}

603

604

605

606

607

608

609

610

611

612

613

614

615

616

617

618

619

620

621

Abbasi, G.; Li, L.; Breivik, K. Global Historical Stocks and Emissions of PBDEs. Environmental Science \& Technology 2019;53:6330-6340

Adetona, O.; Horton, K.; Sjodin, A.; Jones, R.; Hall, D.B.; Aguillar-Villalobos, M.; Cassidy, B.E.; Vena, J.E.; Needham, L.L.; Naeher, L.P. Concentrations of select persistent organic pollutants across pregnancy trimesters in maternal and in cord serum in Trujillo, Peru. Chemosphere 2013;91:1426-33

Aleksa, K.; Carnevale, A.; Goodyer, C.; Koren, G. Detection of polybrominated biphenyl ethers (PBDEs) in pediatric hair as a tool for determining in utero exposure. Forensic Science International 2012;218:37-43

Antignac, J.P.; Main, K.M.; Virtanen, H.E.; Boquien, C.Y.; Marchand, P.; Venisseau, A.; Guiffard, I.; Bichon, E.; Wohlfahrt-Veje, C.; Legrand, A.; Boscher, C.; Skakkebæk, N.E.; Toppari, J.; Le Bizec, B. Country-specific chemical signatures of persistent organic pollutants (POPs) in breast milk of French, Danish and Finnish women. Environmental Pollution 2016;218:728-738

Appenzeller, B.M.R.; Hardy, E.M.; Grova, N.; Chata, C.; Fays, F.; Briand, O.; Schroeder, H.; Duca, R.-C. Hair analysis for the biomonitoring of pesticide exposure: comparison with blood and urine in a rat model. Archives of Toxicology 2017;91:2813-2825

Arbuckle, T.E.; Davis, K.; Marro, L.; Fisher, M.; Legrand, M.; LeBlanc, A.; Gaudreau, 
E.; Foster, W.G.; Choeurng, V.; Fraser, W.D. Phthalate and bisphenol A exposure among pregnant women in Canada-results from the MIREC study. Environment International 2014;68:55-65

Arnich, N.; Tard, A.; Leblanc, J.-C.; Bizec, B.L.; Narbonne, J.-F.; Maximilien, R. Dietary intake of non-dioxin-like PCBs (NDL-PCBs) in France, impact of maximum levels in some foodstuffs. Regulatory Toxicology and Pharmacology $2009 ; 54: 287-293$

Barbounis, E.G.; Tzatzarakis, M.N.; Alegakis, A.K.; Kokkinaki, A.; Karamanos, N.; Tsakalof, A.; Tsatsakis, A.M. Assessment of PCBs exposure in human hair using double focusing high resolution mass spectrometry and single quadrupole mass spectrometry. Toxicology Letters 2012;210:225-231

Behrooz, R.; Barghi, M.; Bahramifar, N.; Esmaili-Sari, A. Organochlorine contaminants in the hair of Iranian pregnant women. Chemosphere $2012 ; 86: 235-241$

Béranger, R.; Hardy, E.M.; Dexet, C.; Guldner, L.; Zaros, C.; Nougadere, A.; Metten, M.-A.; Chevrier, C.; Appenzeller, B.M.R. Multiple pesticide analysis in hair samples of pregnant French women: results from the ELFE national birth cohort. Environment International 2018;120:43-53

Breivik, K.; Sweetman, A.; Pacyna, J.M.; Jones, K.C. Towards a global historical emission inventory for selected PCB congeners-a mass balance approach: 1 . global production and consumption. Science of The Total Environment 2002;290:181-198

Carnevale, A.; Aleksa, K.; Goodyer, C.G.; Koren, G. Investigating the use of hair to assess polybrominated diphenyl ether exposure retrospectively. Therapeutic Drug Monitoring 2014;36:244-251 
647 Carwile, J.L.; Michels, K.B. Urinary bisphenol A and obesity: NHANES 2003-2006.

$648 \quad$ Environmental Research 2011;111:825-830

649 Charles, M.A.; Thierry, X.; Lanoe, J.L.; Bois, C.; Dufourg, M.N.; Popa, R.; Cheminat, 650 M.; Zaros. C.; Geay, B. Cohort Profile: The French National cohort of children 651 ELFE: birth to 5 years. International Journal of Epidemiology 2019; Nov 20

652 Chen, D.; Kannan, K.; Tan, H.L.; Zheng, Z.G.; Feng, Y.L.; Wu, Y.; Widelka, M.

653 Bisphenol analogues other than BPA: environmental occurrence, human

654 exposure, and toxicity: a review. Environmental Science \& Technology $655 \quad 2016 ; 50: 5438-5453$

656 Chen, T.; Niu, P.; Kong, F.; Wang, Y.; Bai, Y.; Yu, D.; Jia, J.; Yang, L.; Fu, Z.; Li, R.; 657 Li, J.; Tian, L.; Sun, Z.; Wang, D.; Shi, Z. Disruption of thyroid hormone levels 658 by decabrominated diphenyl ethers (BDE-209) in occupational workers from a 659 deca-BDE manufacturing plant. Environment International 2018;120:505-515

660 Covaci, A.; Hura, C.; Gheorghe, A.; Neels, H.; Dirtu, A.C. Organochlorine 661 contaminants in hair of adolescents from Iassy, Romania. Chemosphere 662 $2008 ; 72: 16-20$

663

664

665

Dirtu, A.C.; Roberta, C.; Dragan, D.; Raluca, M.; Van Grieken, R.; Neels, H.; Covaci, A. Organohalogenated pollutants in human serum from Iassy, Romania and their relation with age and gender. Environment International 2006;32:797-803

Duca, R.-C.; Hardy, E.; Salquebre, G.; Appenzeller, B.M.R. Hair decontamination procedure prior to multi-class pesticide analysis. Drug Testing and Analysis 2014;6:55-66

Frederiksen, M.; Vorkamp, K.; Thomsen, M.; Knudsen, L.E. Human internal and external exposure to PBDEs - A review of levels and sources. International Journal of Hygiene and Environmental Health 2009;212:109-134 
672 Gentes, M.-L.; Letcher, R.J.; Caron-Beaudoin, É.; Verreault, J. Novel flame retardants 673 in urban-feeding ring-billed gulls from the St. Lawrence River, Canada.

$674 \quad$ Environmental Science \& Technology 2012;46:9735-9744

675 Grova, N.; Hardy, E.M.; Faÿs, F.; Duca, R.C.; Appenzeller, B.M.R. Hair analysis for 676 the biomonitoring of polycyclic aromatic hydrocarbon exposure: comparison with urinary metabolites and DNA adducts in a rat model. Archives of Toxicology 2018;92:3061-3075

679

680

681

682

683

684

685

686

687

688

689

690

691

692

693

694

695

696

Hooper, K.; McDonald, T.A. The PBDEs: An emerging environmental challenge and another reason for breast-milk monitoring programs. Environmental Health Perspectives 2000;108:387-392

Huang, R.-p.; Liu, Z.-h.; Yuan, S.-f.; Yin, H.; Dang, Z.; Wu, P.-x. Worldwide human daily intakes of bisphenol A (BPA) estimated from global urinary concentration data (2000-2016) and its risk analysis. Environmental Pollution 2017;230:143-152

Hurley, S.; Goldberg, D.; Nelson, D.O.; Guo, W.H.; Wang, Y.Z.; Baek, H.G.; Park, J.S.; Petreas, M.; Bernstein, L.; Anton-Culver, H.; Reynolds, P. Temporal evaluation of Polybrominated Diphenyl Ether (PBDE) serum levels in middle-aged and older California women, 2011-2015. Environmental Science \& Technology 2017;51:4697-4704

Jin, H.; Zhu, J.; Chen, Z.; Hong, Y.; Cai, Z. Occurrence and Partitioning of Bisphenol Analogues in Adults’ Blood from China. Environmental Science \& Technology 2018;52:812-820

Kalloo, G.; Wellenius, G.A.; McCandless, L.; Calafat, A.M.; Sjodin, A.; Karagas, M.; Chen, A.; Yolton, K.; Lanphear, B.P.; Braun, J.M. Profiles and predictors of environmental chemical mixture exposure among pregnant women: the health 
697

698

699

700

701

702

703

704

705

706

707

708

709

710

711

712

713

714

715

716

717

718

719

720

721

outcomes and measures of the environment study. Environmental Science \& Technology 2018;52:10104-10113

Kang, Y.; Wang, H.S.; Cheung, K.C.; Wong, M.H. Polybrominated diphenyl ethers (PBDEs) in indoor dust and human hair. Atmospheric Environment $2011 ; 45: 2386-2393$

Karzi, V.; Tzatzarakis, M.N.; Vakonaki, E.; Alegakis, T.; Katsikantami, I.; Sifakis, S.; Rizos, A.; Tsatsakis, A.M. Biomonitoring of bisphenol A, triclosan and perfluorooctanoic acid in hair samples of children and adults. Journal of Applied Toxicology 2018;38:1144-1152

Kintz, P.; Salomone, A.; Vincenti, M. Hair analysis in clinical and forensic toxicology. Academic Press; 2015

Król, S.; Namieśnik, J.; Zabiegała, B. Occurrence and levels of polybrominated diphenyl ethers (PBDEs) in house dust and hair samples from Northern Poland; an assessment of human exposure. Chemosphere 2014;110:91-96

La Guardia, M.J.; Hale, R.C.; Harvey, E. Detailed polybrominated diphenyl ether (PBDE) congener composition of the widely used penta-, octa-, and deca-PBDE technical flame-retardant mixtures. Environmental Science \& Technology 2006;40:6247-6254

Larsson, K.; Lindh, C.H.; Jönsson, B.A.G.; Giovanoulis, G.; Bibi, M.; Bottai, M.; Bergström, A.; Berglund, M. Phthalates, non-phthalate plasticizers and bisphenols in Swedish preschool dust in relation to children's exposure. Environment International 2017;102:114-124

Lee, C.; Kim, C.H.; Kim, S.; Cho, S.-H. Simultaneous determination of bisphenol A and estrogens in hair samples by liquid chromatography-electrospray tandem mass spectrometry. Journal of Chromatography B 2017;1058:8-13 
722 Lehmler, H.J.; Liu, B.Y.; Gadogbe, M.; Bao, W. Exposure to bisphenol A, bisphenol F,

723

724 and bisphenol S in US adults and children: The national health and nutrition examination survey 2013-2014. Acs Omega 2018;3:6523-6532

Liao, C.; Kannan, K. Concentrations and profiles of bisphenol A and other bisphenol analogues in foodstuffs from the United States and their implications for human exposure. Journal of Agricultural and Food Chemistry 2013;61:4655-4662

Liao, C.Y.; Kannan, K. A survey of alkylphenols, bisphenols, and triclosan in personal care products from China and the United States. Archives of Environmental Contamination and Toxicology 2014;67:50-59

Liu, B.; Lehmler, H.-J.; Sun, Y.; Xu, G.; Liu, Y.; Zong, G.; Sun, Q.; Hu, F.B.; Wallace, R.B.; Bao, W. Bisphenol A substitutes and obesity in US adults: analysis of a population-based, cross-sectional study. The Lancet Planetary Health 2017;1:e114-e122

Liu, L.Y.; He, K.; Hites, R.A.; Salamova, A. Hair and nails as noninvasive biomarkers of human exposure to brominated and organophosphate flame retardants. Environmental Science \& Technology 2016;50:3065-3073

Mai, B.X.; Chen, S.J.; Luo, X.J.; Chen, L.G.; Yang, Q.S.; Sheng, G.Y.; Peng, P.G.; Fu, J.M.; Zeng, E.Y. Distribution of polybrominated diphenyl ethers in sediments of the Pearl River Delta and adjacent South China Sea. Environmental Science \& Technology 2005;39:3521-3527

Malarvannan, G.; Isobe, T.; Covaci, A.; Prudente, M.; Tanabe, S. Accumulation of brominated flame retardants and polychlorinated biphenyls in human breast milk and scalp hair from the Philippines: Levels, distribution and profiles. Science of The Total Environment 2013;442:366-379

Meeker, J.D.; Ferguson, K.K. Relationship between urinary phthalate and bisphenol A 
concentrations and serum thyroid measures in US adults and adolescents from the National Health and Nutrition Examination Survey (NHANES) 2007-2008. Environmental Health Perspectives 2011;119:1396-1402

Michałowicz, J. Bisphenol A-sources, toxicity and biotransformation. Environmental Toxicology and Pharmacology 2014;37:738-758

Naudin, G.; Bastien, P.; Mezzache, S.; Trehu, E.; Bourokba, N.; Appenzeller, B.M.R.; Soeur, J.; Bornschlögl, T. Human pollution exposure correlates with accelerated ultrastructural degradation of hair fibers. Proc Natl Acad Sci U S A 2019; 116:18410-18415

Nehring, I.; Staniszewska, M.; Falkowska, L. Human Hair, Baltic Grey Seal (Halichoerus grypus) Fur and Herring Gull (Larus argentatus) Feathers as Accumulators of Bisphenol A and Alkylphenols. Archives of Environmental Contamination and Toxicology 2017;72:552-561

Norström, K.; Czub, G.; McLachlan, M.S.; Hu, D.; Thorne, P.S.; Hornbuckle, K.C. External exposure and bioaccumulation of PCBs in humans living in a contaminated urban environment. Environment International 2010;36:855-861

Owczarek, K.; Kubica, P.; Kudłak, B.; Rutkowska, A.; Konieczna, A.; Rachoń, D.; Namieśnik, J.; Wasik, A. Determination of trace levels of eleven bisphenol A analogues in human blood serum by high performance liquid chromatography-tandem mass spectrometry. Science of The Total Environment 2018;628-629:1362-1368

Palazzi, P.; Mezzache, S.; Bourokba, N.; Hardy, E.M.; Schritz, A.; Bastien, P.; Emond, C.; Li, J.; Soeur, J.; Appenzeller, B.M.R. Exposure to polycyclic aromatic hydrocarbons in women living in the Chinese cities of BaoDing and Dalian revealed by hair analysis. Environment International 2018;121:1341-1354 
Peng, F.-J.; Hardy, E. M.; Mezzache, S.; Bourokba, N.; Palazzi, P.; Stojiljkovic, N.; Bastien, P.; Li, J.; Soeur, J.; Appenzeller, B. M. R., Exposure to multiclass pesticides among female adult population in two Chinese cities revealed by hair analysis. Environment International 2020;138:105633

Pinson, A.; Bourguignon, J.P.; Parent, A.S. Exposure to endocrine disrupting chemicals and neurodevelopmental alterations. Andrology 2016;4:706-722

Poon, S.; Wade, M.G.; Aleksa, K.; Rawn, D.F.K.; Carnevale, A.; Gaertner, D.W.; Sadler, A.; Breton, F.; Koren, G.; Ernest, S.R.; Lalancette, C.; Robaire, B.; Hales, B.F.; Goodyer, C.G. Hair as a biomarker of systemic exposure to polybrominated diphenyl ethers. Environmental Science \& Technology 2014;48:14650-14658

Qiao, L.; Zheng, X.B.; Zheng, J.; Chen, S.J.; Zhong, C.Q.; Chen, J.H.; Yang, Z.Y.; Mai, B.X. Legacy and currently used organic contaminants in human hair and hand wipes of female e-waste dismantling workers and workplace dust in South China. Environmental Science \& Technology 2019;53:2820-2829

Rawn, D.F.K.; Ryan, J.J.; Sadler, A.R.; Sun, W.-F.; Haines, D.; Macey, K.; Van Oostdam, J. PCDD/F and PCB concentrations in sera from the Canadian Health Measures Survey (CHMS) from 2007 to 2009. Environment International $2012 ; 47: 48-55$

Ritter, R.; Scheringer, M.; MacLeod, M.; Moeckel, C.; Jones, K.C.; Hungerbuhler, K. Intrinsic Human Elimination Half-Lives of Polychlorinated Biphenyls Derived from the Temporal Evolution of Cross-Sectional Biomonitoring Data from the United Kingdom. Environmental Health Perspectives 2011;119:225-231

Rochester, J.R.; Bolden, A.L. Bisphenol S and F: a systematic review and comparison of the hormonal activity of bisphenol A substitutes. Environmental Health Perspectives 2015;123:643-650 
797 Rodríguez-Gómez, R.; Martín, J.; Zafra-Gómez, A.; Alonso, E.; Vílchez, J.L.;

798 Navalón, A. Biomonitoring of 21 endocrine disrupting chemicals in human hair

799 samples using ultra-high performance liquid chromatography-tandem mass

$800 \quad$ spectrometry. Chemosphere 2017;168:676-684

801 Rohart, F.; Gautier, B.; Singh, A.; Le Cao, K.A. mixOmics: An R package for 'omics

802

803

804

805

806

807

808

809

810

811

812

813

814

815

816

817

818

819

820

821

feature selection and multiple data integration. Plos Computational Biology $2017 ; 13$

Rudel, R.A.; Perovich, L.J. Endocrine disrupting chemicals in indoor and outdoor air. Atmospheric Environment 2009;43:170-181

Safe, S. Polychlorinated biphenyls (PCBs) and polybrominated biphenyls (PBBs): biochemistry, toxicology, and mechanism of action. Crc Critical Reviews in Toxicology 1984;13:319-395

Tadeo, J.L.; Sanchez-Brunete, C.; Miguel, E. Determination of polybrominated diphenyl ethers in human hair by gas chromatography-mass spectrometry. Talanta 2009;78:138-143

Tang, L.; Lei, B.; Xu, G.; Ma, J.; Lei, J.-Q.; Jin, S.-Q.; Hu, G.-Y.; Wu, M.-H. Polybrominated diphenyl ethers in human hair from the college environment: comparison with indoor dust. Bulletin of Environmental Contamination and Toxicology 2013;91:377-381

Tsatsakis, A.M.; Tzatzarakis, M.N.; Tutudaki, M.; Babatsikou, F.; Alegakis, A.K.; Koutis, C. Assessment of levels of organochlorine pesticides and their metabolites in the hair of a Greek rural human population. Human \& Experimental Toxicology 2008;27:933-940

Tzatzarakis, M.N.; Vakonaki, E.; Kavvalakis, M.P.; Barmpas, M.; Kokkinakis, E.N.; Xenos, K.; Tsatsakis, A.M. Biomonitoring of bisphenol A in hair of Greek 
Van den Berg, M.; Houba, R.; Leslie, H.A.; Canton, R.F.; Thomsen, C.; Becher, G.; Alvarez-Pedrerol, M.; Deu, J.S.; Steiner, M.; van Tongeren, M.; Brunekreef, B.; de Boer, J. Serum levels of decabromodiphenyl ether (BDE-209) in women from different European countries and possible relationships with lifestyle and diet. Environment International 2017;107:16-24

Wang, W.; Abualnaja, K.O.; Asimakopoulos, A.G.; Covaci, A.; Gevao, B.; Johnson-Restrepo, B.; Kumosani, T.A.; Malarvannan, G.; Minh, T.B.; Moon, H.-B.; Nakata, H.; Sinha, R.K.; Kannan, K. A comparative assessment of human exposure to tetrabromobisphenol A and eight bisphenols including bisphenol A via indoor dust ingestion in twelve countries. Environment International $2015 ; 83: 183-191$

Wen, S.; Yang, F.-X.; Gong, Y.; Zhang, X.-L.; Hui, Y.; Li, J.-G.; Liu, A.-L.; Wu, Y.-N.; Lu, W.-Q.; Xu, Y. Elevated Levels of Urinary 8-Hydroxy-2' -deoxyguanosine in Male Electrical and Electronic Equipment Dismantling Workers Exposed to High Concentrations of Polychlorinated Dibenzo-p-dioxins and Dibenzofurans, Polybrominated Diphenyl Ethers, and Polychlorinated Biphenyls. Environmental Science \& Technology 2008;42:4202-4207

World Health Organization. Brominated diphenyl ethers. WHO IPCS Environmental Health Criteria Document. No 162; 1994.

WHO/UNEP. State of the Science of Endocrine Disrupting Chemicals - 2012:

Summary for Decision Makers. In: Bergman, A.; Heindel, J.J.; Jobling, S.; Kidd, 
K.A.; Zoeller, R.T. (Eds.), pp. 1-30 (Geneva); 2013.

847 Xing, Y.; Lu, Y.; Dawson, R.W.; Shi, Y.; Zhang, H.; Wang, T.; Liu, W.; Ren, H. A

848

849

850

851

852

853

854

855

856

857

858

859

860

861

862

863

864

865

866

867

868

869 spatial temporal assessment of pollution from PCBs in China. Chemosphere 2005;60:731-739

Zhao, G.; Wang, Z.; Dong, M.H.; Rao, K.; Luo, J.; Wang, D.; Zha, J.; Huang, S.; Xu, Y.; Ma, M. PBBs, PBDEs, and PCBs levels in hair of residents around e-waste disassembly sites in Zhejiang Province, China, and their potential sources. Science of The Total Environment 2008;397:46-57

Zheng, J.; Chen, K.-H.; Luo, X.-J.; Yan, X.; He, C.-T.; Yu, Y.-J.; Hu, G.-C.; Peng, X.-W.; Ren, M.-Z.; Yang, Z.-Y.; Mai, B.-X. Polybrominated Diphenyl Ethers (PBDEs) in Paired Human Hair and Serum from e-Waste Recycling Workers: Source Apportionment of Hair PBDEs and Relationship between Hair and Serum. Environmental Science \& Technology 2014;48:791-796

Zheng, J.; Luo, X.-J.; Yuan, J.-G.; Wang, J.; Wang, Y.-T.; Chen, S.-J.; Mai, B.-X.; Yang, Z.-Y. Levels and sources of brominated flame retardants in human hair from urban, e-waste, and rural areas in South China. Environmental Pollution 2011;159:3706-3713

Zheng, J.; Yu, L.H.; Chen, S.J.; Hu, G.C.; Chen, K.H.; Yan, X.; Luo, X.J.; Zhang, S.K.; Yu, Y.J.; Yang, Z.Y.; Mai, B.X. Polychlorinated biphenyls (PCBs) in human hair and serum from e-waste recycling workers in southern China: Concentrations, chiral signatures, correlations, and source identification. Environmental Science \& Technology 2016;50:1579-1586

Zota, A.R.; Mitro, S.D.; Robinson, J.F.; Hamilton, E.G.; Park, J.-S.; Parry, E.; Zoeller, R.T.; Woodruff, T.J. Polybrominated diphenyl ethers (PBDEs) and hydroxylated 
870 PBDE metabolites (OH-PBDEs) in maternal and fetal tissues, and associations with

871 fetal cytochrome P450 gene expression. Environment International 2018;112:269-278 


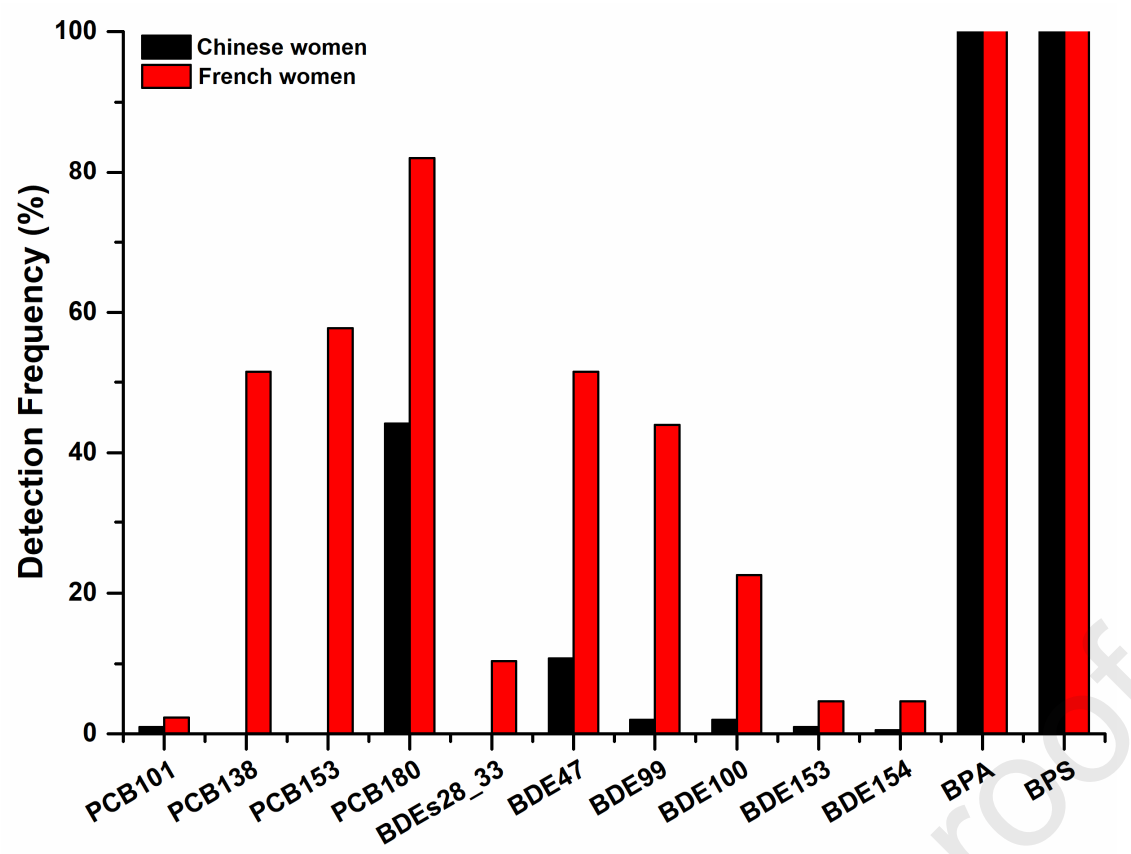

873 Figure 1. Detection frequencies of target compounds in hair samples collected from 874 the Chinese ( $n=204$; black bars) and the French women ( $=311$; red bars). 


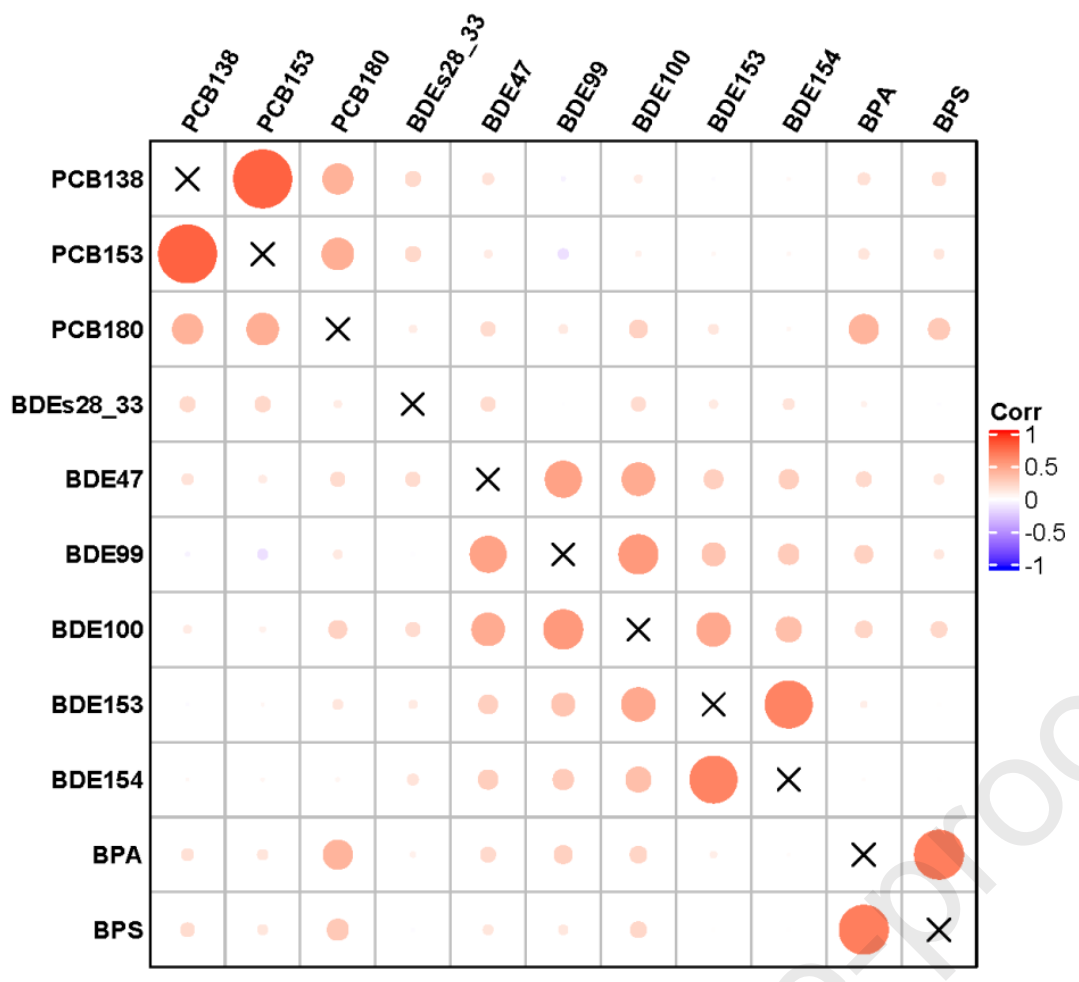

876 Figure 2. Heatmap showing pairwise correlations between analyte concentrations in

877 hair samples collected from the French women in 2011. Blue and red colors indicate 878 negative and positive correlations based on Spearman tests, respectively. The size of 879 circle symbols represents the strength of correlations. A cross symbolizes that the 880 correlation coefficient is 1 . Only analytes detected in more than ten samples are 881 presented in the graph. Abbreviations for all compounds are shown in the Supporting 882 Information. 

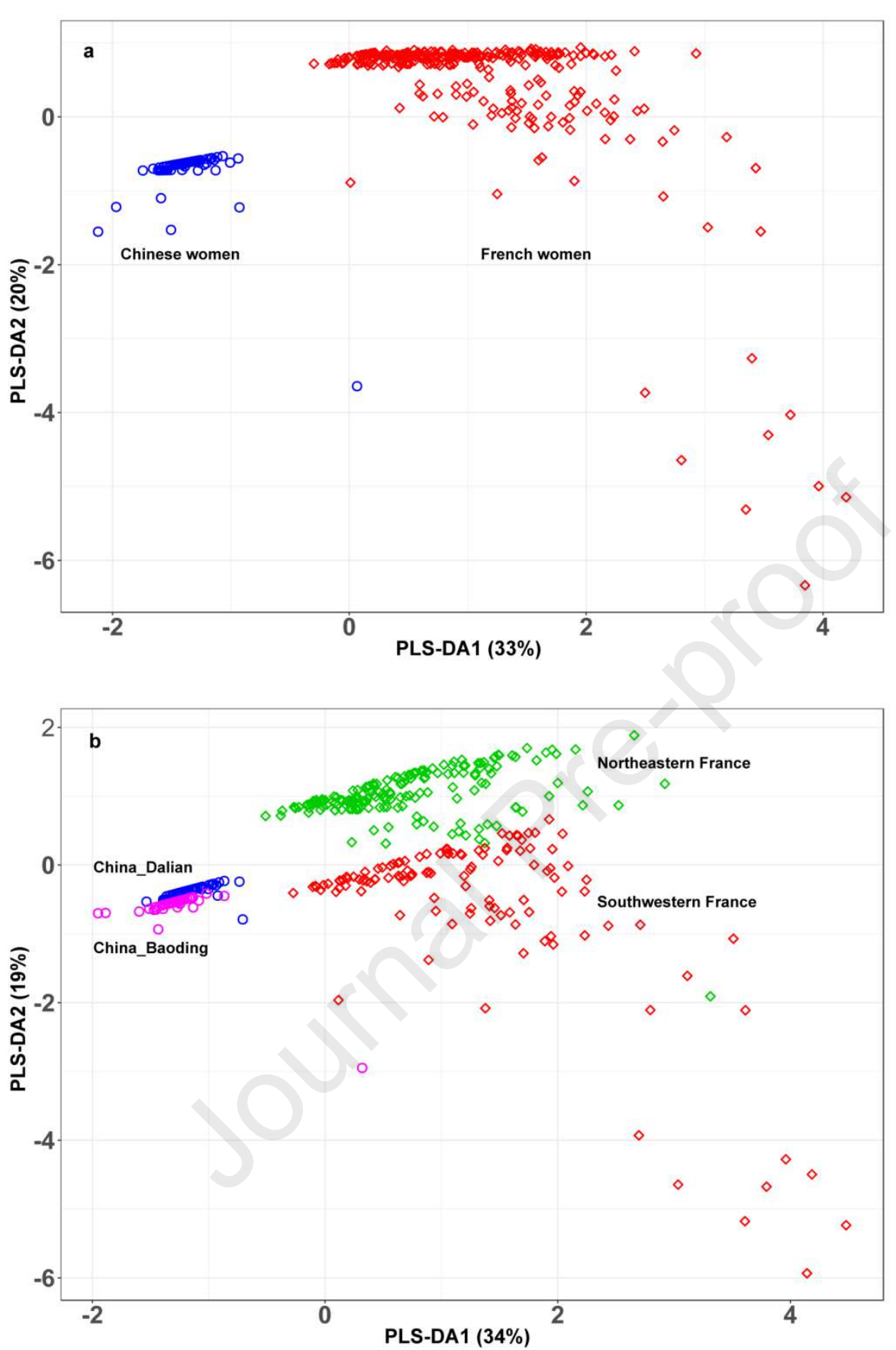

Figure 3. Sample plots of partial least squared-discriminant analyses (PLS-DA) performed on POPs (i.e., PCBs and PBDEs) determined in hair samples collected from the Chinese $(n=204)$ and the French women $(n=311)$. In graph a, blue circle and red diamond symbols indicate hair samples from the Chinese and the French women, respectively; In graph b, blue and magenta circle symbols represent hair samples from the Chinese women living in Dalian $(n=102)$ and Baoding $(n=102)$, respectively, while green and red diamond symbols indicate hair samples from the French women living in northeast $(n=182)$ and southwest $(n=129)$, respectively. 
894

895

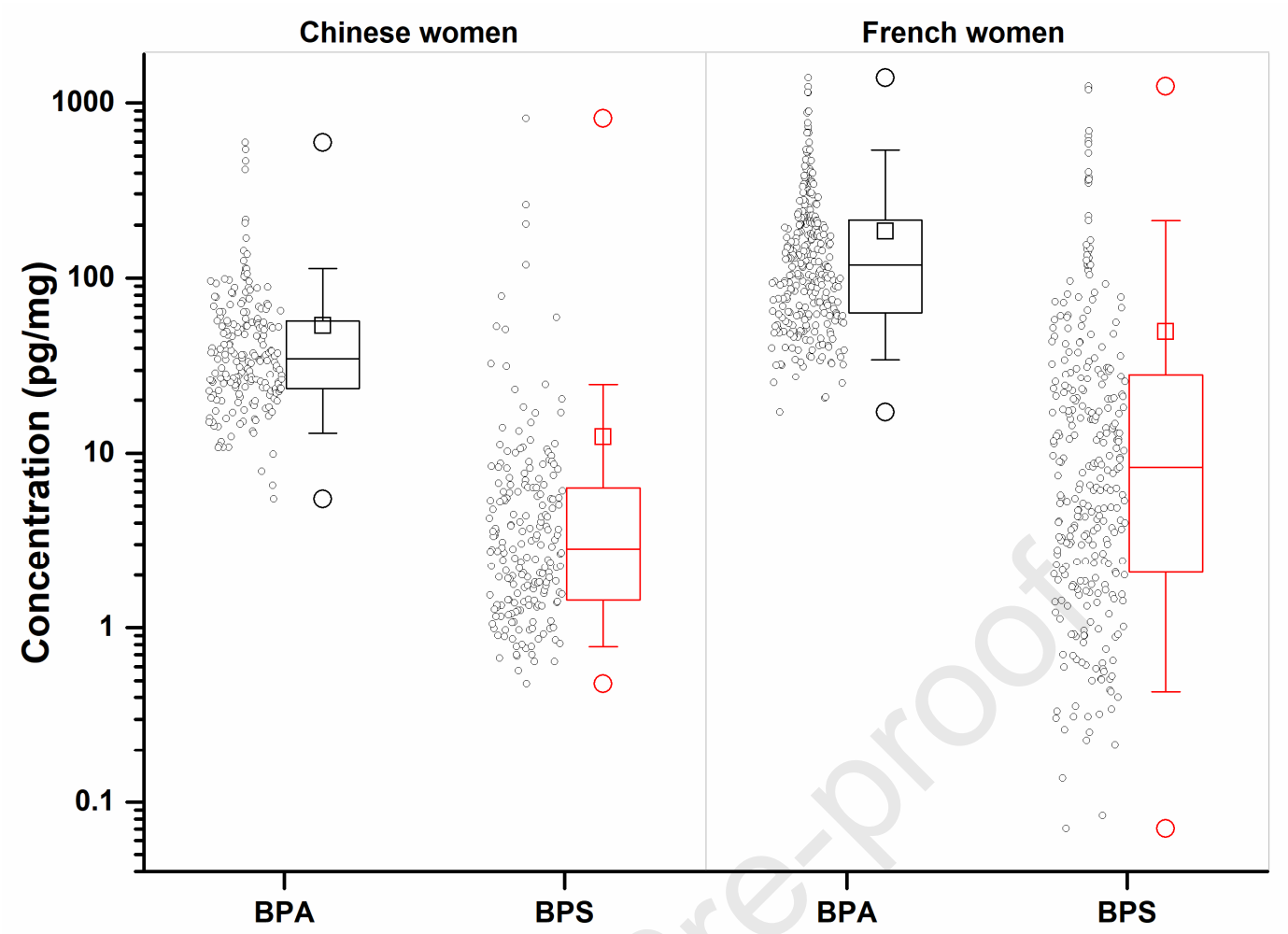

896 Figure 4. Concentrations of BPA and BPS in hair samples collected from the Chinese $897(n=204)$ and the French women $(n=311)$. Black circles indicate hair samples. Boxes 898 represent $25-75$ percentiles, with whiskers of $5^{\text {th }}$ and $95^{\text {th }}$ percentiles. The lowest and 899 highest circles indicate the minimum and maximum. Lines inside the boxes represent 900 medians while squares represent means.

901

902 
903 Table 1. Concentrations (pg/mg) of PCBs, BDEs, BPA and BPS in human hair collected from the Chinese and the French women.

\begin{tabular}{|c|c|c|c|c|c|c|c|c|c|c|c|c|c|c|c|c|c|c|}
\hline \multirow[b]{2}{*}{ Analytes } & \multicolumn{8}{|c|}{ China $(\mathrm{n}=204)$} & \multicolumn{8}{|c|}{ France $(\mathrm{n}=311)$} & \multirow[b]{2}{*}{$p$-value } & \multirow[b]{2}{*}{ LOD } \\
\hline & $\begin{array}{l}\mathrm{DF} \\
(\%)\end{array}$ & $\begin{array}{l}\text { Arithmetic } \\
\text { mean }\end{array}$ & Min & $25 \% \mathrm{P}$ & $50 \% \mathrm{P}$ & $75 \% \mathrm{P}$ & $95 \% \mathrm{P}$ & Max & $\mathrm{DF}(\%)$ & $\begin{array}{l}\text { Arithmetic } \\
\text { mean }\end{array}$ & Min & $25 \% \mathrm{P}$ & $50 \% \mathrm{P}$ & $75 \% \mathrm{P}$ & $95 \% \mathrm{P}$ & Max & & \\
\hline PCB 101 & 1 & 4.63 & $<$ LOD & $<$ LOD & $<$ LOD & $<$ LOD & $<$ LOD & 63.2 & 2 & 0.07 & $<$ LOD & $<$ LOD & $<$ LOD & $<\mathrm{LOD}$ & $<$ LOD & 1.12 & 0.558 & 0.26 \\
\hline РCB 138 & 0 & - & $<\mathrm{LOD}$ & $<\mathrm{LOD}$ & $<$ LOD & $<$ LOD & $<\mathrm{LOD}$ & $<$ LOD & 45 & 0.37 & $<\mathrm{LOD}$ & $<\mathrm{LOD}$ & $<\mathrm{LOD}$ & 0.28 & 0.83 & 3.36 & $2.61 \mathrm{E}-28$ & 0.03 \\
\hline РCB 153 & 0 & - & $<\mathrm{LOD}$ & $<\mathrm{LOD}$ & $<\mathrm{LOD}$ & $<\mathrm{LOD}$ & $<\mathrm{LOD}$ & $<\mathrm{LOD}$ & 50 & 0.63 & $<$ LOD & $<\mathrm{LOD}$ & $<\mathrm{LOD}$ & 0.3 & 0.746 & 9.68 & 4.07E-32 & 0.08 \\
\hline РCB 180 & 44 & 0.24 & $<\mathrm{LOD}$ & $<\mathrm{LOD}$ & $<\mathrm{LOD}$ & 0.12 & 0.47 & 2.12 & 82 & 0.54 & $<\mathrm{LOD}$ & 0.1 & 0.25 & 0.45 & 1.12 & 6.79 & $6.80 \mathrm{E}-28$ & 0.02 \\
\hline BDEs 28_33 & 0 & - & $<\mathrm{LOD}$ & $<\mathrm{LOD}$ & $<\mathrm{LOD}$ & $<\mathrm{LOD}$ & $<\mathrm{LOD}$ & $<\mathrm{LOD}$ & 7 & 0.26 & $<\mathrm{LOD}$ & $<\mathrm{LOD}$ & $<\mathrm{LOD}$ & $<\mathrm{LOD}$ & 0.13 & 3.37 & 7.23E-05 & 0.04 \\
\hline BDE 47 & 11 & 0.75 & $<\mathrm{LOD}$ & $<\mathrm{LOD}$ & $<\mathrm{LOD}$ & $<\mathrm{LOD}$ & 0.55 & 7.87 & 57 & 16 & $<\mathrm{LOD}$ & $<\mathrm{LOD}$ & 1.37 & 5.09 & 30.9 & 152 & $4.81 \mathrm{E}-29$ & 0.15 \\
\hline BDE 99 & 2 & 1.02 & $<\mathrm{LOD}$ & $<\mathrm{LOD}$ & $<\mathrm{LOD}$ & $<\mathrm{LOD}$ & $<\mathrm{LOD}$ & 14.8 & 49 & 38.5 & $<\mathrm{LOD}$ & $<\mathrm{LOD}$ & $<\mathrm{LOD}$ & 4.02 & 26.6 & 396 & $2.94 \mathrm{E}-29$ & 0.63 \\
\hline BDE 100 & 2 & 0.66 & $<\mathrm{LOD}$ & $<\mathrm{LOD}$ & $<\mathrm{LOD}$ & $<\mathrm{LOD}$ & $<\mathrm{LOD}$ & 9.49 & 20 & 5.5 & $<\mathrm{LOD}$ & $<\mathrm{LOD}$ & $<\mathrm{LOD}$ & $<\mathrm{LOD}$ & 4.23 & 73.7 & $2.01 \mathrm{E}-09$ & 0.23 \\
\hline BDE 153 & 1 & 0.3 & $<\mathrm{LOD}$ & $<\mathrm{LOD}$ & $<\mathrm{LOD}$ & $<\mathrm{LOD}$ & $<\mathrm{LOD}$ & 4.75 & 5 & 14.7 & $<\mathrm{LOD}$ & $<\mathrm{LOD}$ & $<\mathrm{LOD}$ & $<\mathrm{LOD}$ & 0.98 & 234 & 0.011 & 0.91 \\
\hline BDE 154 & 0.5 & 0.09 & $<\mathrm{LOD}$ & $<\mathrm{LOD}$ & $<$ LOD & $<\mathrm{LOD}$ & $<$ LOD & 1.61 & 4 & 7.72 & $<$ LOD & $<$ LOD & $<$ LOD & $<$ LOD & $<$ LOD & 112 & 0.017 & 0.67 \\
\hline Bisphenol A & 100 & 72.6 & 5.47 & 23.4 & 34.9 & 57.2 & 122 & 596 & 100 & 199 & 17.1 & 63.4 & 118 & 213 & 541 & 1398 & $2.53 \mathrm{E}-43$ & 5.47 \\
\hline Bisphenol S & 100 & 62.1 & 0.48 & 1.43 & 2.84 & 6.34 & 29.9 & 817 & 100 & 149 & 0.07 & 2.11 & 8.32 & 27.9 & 217 & 1246 & $1.46 \mathrm{E}-10$ & 0.07 \\
\hline
\end{tabular}

904 DF: detection frequency; Min: minimum; LOD: limit of detection; Max: maximum; $p$-values were obtained from Mann-Whitney U-test. 


\section{Highlights}

- Hair analysis was used to assess exposure of two female populations to multiclass EDCs

- All PCBs and PBDEs analyzed were more frequently detected in French women than in Chinese women

- PCB 180 was detected in $82 \%$ of the French women and $44 \%$ of the Chinese women

- BPA and BPS were found in $100 \%$ of the hair samples from both female populations

- French women had significantly higher levels of BPA and BPS than the Chinese women 


\section{Declaration of interests}

$\bigotimes$ The authors declare that they have no known competing financial interests or personal relationships that could have appeared to influence the work reported in this paper.

$\square$ The authors declare the following financial interests/personal relationships which may be considered as potential competing interests: 


\section{Human exposure to PCBs, PBDEs and bisphenols revealed by hair analysis: a comparison between Chinese and French women}

Feng-Jiao Peng ${ }^{\text {a }}{ }^{*}$, Emilie M. Hardy ${ }^{\text {a }}$, Rémi Béranger ${ }^{\mathrm{b}}$, Sakina Mezzache ${ }^{\mathrm{c}}$, Nasrine Bourokba ${ }^{\mathrm{d}}$, Philippe Bastien ${ }^{\mathrm{c}}$, Jing Li ${ }^{\mathrm{e}}$, Cécile Zaros ${ }^{\mathrm{f},}$ Cécile Chevrier ${ }^{\mathrm{b}}$, Paul Palazzi $^{\text {a }}$, Jeremie Soeur ${ }^{\mathrm{c}}$, Brice M.R. Appenzeller ${ }^{\mathrm{a}}$

a Human Biomonitoring Research Unit, Department of Population Health, Luxembourg Institute of Health, 1 A-B rue Thomas Edison, 1445 Strassen, Luxembourg

${ }^{\mathrm{b}}$ Univ Rennes, CHU Rennes, Inserm, EHESP, Irset (Institut de recherche en santé, environnement et travail) - UMR_S 1085, F-35000 Rennes, France

c L'Oréal Research and Innovation, 1 avenue Eugène Schueller BP22, 93601 Aulnay-sous-Bois, France

${ }^{\mathrm{d}}$ L'Oréal Research and Innovation, Biopolis Drive, Synapse, 138623, Singapore

${ }^{\mathrm{e}}$ L'Oréal Research and Innovation, No. 550 JinYu Rd., Pudong New Area, China

${ }^{\mathrm{f}}$ INSERM, Joint Unit INED-INSERM-EFS, Paris, France.

Number of pages: 12

Number of tables: 6

Number of figures: 1 


\section{Contents:}

Table S1 Physicochemical properties of target compounds in this study.

Table S2 Characteristics of participants providing hair samples for analysis of target pollutants.

Table S3 Method validation parameters of analysis of target PCBs, PBDEs and BPs in hair.

Table S4 Concentrations (pg/mg) of PCBs, BDEs, BPA and BPS in human hair collected from the Chinese women in Baoding and Dalian and the French women in northeast and southwest.

Table S5 Multiple linear regression models of dominant chemicals on population characteristics.

Table S6 Comparison of concentrations of target compounds in human hair from various countries.

Fig. S1. Concentrations of BPA and BPS in hair samples from the Chinese women in Baoding $(n=102)$, the Chinese women in Dalian $(n=102)$, the French women in northeast $(n=182)$, and the French women in southwest $(n=129)$.

\section{References}


Table S1 Physicochemical properties of target compound in this study.

\begin{tabular}{|c|c|c|c|c|c|c|}
\hline Analyte & Abbreviation & CAS & Formula & M.W. (mol/g) & Log Kow & References \\
\hline 2,2',4,5,5'-Pentachlorobiphenyl & PCB101 & $37680-73-2$ & $\mathrm{C}_{12} \mathrm{H}_{5} \mathrm{Cl}_{5}$ & 326.43 & 6.44 & Veith et al. (1979) \\
\hline 2,2',3',4,4',5-Hexachlorobiphenyl & PCB138 & $35065-28-2$ & $\mathrm{C}_{12} \mathrm{H}_{4} \mathrm{Cl}_{6}$ & 360.88 & 6.83 & Norström et al. (2010) \\
\hline 2,2',4,4',5,5'-Hexachlorobiphenyl & PCB153 & $35065-27-1$ & $\mathrm{C}_{12} \mathrm{H}_{4} \mathrm{Cl}_{6}$ & 360.88 & 6.92 & Norström et al. (2010) \\
\hline 2,2',3,4,4',5,5'-Heptachlorobiphenyl & PCB180 & $35065-29-3$ & $\mathrm{C}_{12} \mathrm{H}_{3} \mathrm{Cl}_{7}$ & 395.32 & 7.62 & Norström et al. (2010) \\
\hline 2,4,4'-Tribromodiphenyl ether & BDE28 & $41318-75-6$ & $\mathrm{C}_{12} \mathrm{H}_{7} \mathrm{Br}_{3} \mathrm{O}$ & 406.89 & 5.88 & Llorca-Porcel et al. (2006) \\
\hline 2',3,4-Tribromodiphenyl ether & BDE33 & $147217-78-5$ & $\mathrm{C}_{12} \mathrm{H}_{7} \mathrm{Br}_{3} \mathrm{O}$ & 406.89 & 5.88 & Llorca-Porcel et al. (2006) \\
\hline 2,2',4,4'-Tetrabromodiphenyl ether & BDE47 & $5436-43-1$ & $\mathrm{C}_{12} \mathrm{H}_{6} \mathrm{Br}_{4} \mathrm{O}$ & 485.79 & 6.77 & Llorca-Porcel et al. (2006) \\
\hline 2,2',4,4',5-Pentabromodiphenyl & BDE99 & $60348-60-9$ & $\mathrm{C}_{12} \mathrm{H}_{5} \mathrm{Br}_{5} \mathrm{O}$ & 564.69 & 7.66 & Llorca-Porcel et al. (2006) \\
\hline 2,2',4,4',6-Pentabromodiphenyl & BDE100 & $189084-64-8$ & $\mathrm{C}_{12} \mathrm{H}_{5} \mathrm{Br}_{5} \mathrm{O}$ & 564.69 & 7.66 & Llorca-Porcel et al. (2006) \\
\hline 2,2',4,4',5,5'-Hexabromodiphenyl & BDE153 & $68631-49-2$ & $\mathrm{C}_{12} \mathrm{H}_{4} \mathrm{Br}_{6} \mathrm{O}$ & 643.58 & 8.55 & Llorca-Porcel et al. (2006) \\
\hline 2,2',4,4',5,6'-Hexabromodiphenyl & BDE154 & $207122-15-4$ & $\mathrm{C}_{12} \mathrm{H}_{4} \mathrm{Br}_{6} \mathrm{O}$ & 643.58 & 8.55 & Llorca-Porcel et al. (2006) \\
\hline Bisphenol A & $\mathrm{BPA}$ & $80-05-7$ & $\mathrm{C}_{15} \mathrm{H}_{16} \mathrm{O}_{2}$ & 228.29 & 3.32 & Chen et al. (2016) \\
\hline Bisphenol S & BPS & $80-09-1$ & $\mathrm{C}_{12} \mathrm{H}_{10} \mathrm{O}_{4} \mathrm{~S}$ & 250.27 & 1.65 & Michałowicz et al. (2014) \\
\hline
\end{tabular}


Table S2 Characteristics of participants providing hair samples for analysis of target pollutants.

\begin{tabular}{llllll} 
& \multicolumn{2}{l}{ Chinese women $(\mathrm{n}=204)$} & & \multicolumn{2}{c}{ French women $(\mathrm{n}=311)$} \\
\cline { 2 - 3 } Characteristics & $\mathrm{N}(\%)$ & Mean \pm STD & & $\mathrm{N}(\%)$ & Mean \pm STD \\
\hline Age $^{\text {a }}$ & 204 & $34.2 \pm 5.7$ & & 310 & $30.1 \pm 5.0$ \\
BMI $^{\text {a }}$ & 204 & $22.7 \pm 3.4$ & & 310 & $23.2 \pm 4.6$
\end{tabular}

Education $^{\text {a }}$

High school or less

Smoking habit ${ }^{\text {b }}$

Non-smoker

Smoker

Consumption frequency of fish/seafood

$\begin{array}{lll}<1 \text { time/week } & 62(30.4 \%) & \text { NA } \\ 1-3 \text { times/week } & 126(61.8 \%) & \text { NA } \\ 4-7 \text { times/week } & 16(7.8 \%) & \text { NA }\end{array}$

Consumption frequency of fish ${ }^{c}$

$\begin{array}{lll}<1 \text { time/month } & \text { NA } & 93(29.9 \%) \\ \geq 1 \text { time/month } & \text { NA } & 182(58.5 \%)\end{array}$

BMI, body mass index;

${ }^{a}$ one missing value for the French women;

${ }^{\mathrm{b}}$ two missing values for the French women;

${ }^{c}$ Thirty six missing values for the French women;

NA, not applicable. 
Table S3 Method validation parameters of analysis of target PCBs, PBDEs and BPs in hair.

\begin{tabular}{|c|c|c|c|c|c|c|c|c|c|c|c|c|c|c|c|c|c|}
\hline \multirow[b]{2}{*}{ Compound } & \multirow[b]{2}{*}{ Analysis mode } & \multirow[b]{2}{*}{ ISTD } & \multirow[b]{2}{*}{$\mathrm{R}^{2}$} & \multirow[b]{2}{*}{$\begin{array}{l}\mathrm{LOQ} \\
(\mathrm{pg} / \mathrm{mg})\end{array}$} & \multicolumn{5}{|c|}{ Accuracy $(\% ; \mathrm{n}=5)$} & \multicolumn{5}{|c|}{ Variability $(\% ; \mathrm{n}=5)$} & \multicolumn{3}{|c|}{ Recovery (\%) } \\
\hline & & & & & LOQ & $\begin{array}{l}0.1 \\
\mathrm{pg} / \mathrm{mg}\end{array}$ & $\begin{array}{l}1 \\
\mathrm{pg} / \mathrm{mg}\end{array}$ & $\begin{array}{l}10 \\
\mathrm{pg} / \mathrm{mg}\end{array}$ & $\begin{array}{l}100 \\
\mathrm{pg} / \mathrm{mg}\end{array}$ & LOQ & $\begin{array}{l}0.1 \\
\mathrm{pg} / \mathrm{mg}\end{array}$ & $\begin{array}{l}1 \\
\mathrm{pg} / \mathrm{mg}\end{array}$ & $\begin{array}{l}10 \\
\mathrm{pg} / \mathrm{mg}\end{array}$ & $\begin{array}{l}100 \\
\mathrm{pg} / \mathrm{mg}\end{array}$ & $\begin{array}{l}1 \\
\mathrm{pg} / \mathrm{mg}\end{array}$ & $\begin{array}{l}10 \\
\mathrm{pg} / \mathrm{mg}\end{array}$ & $\begin{array}{l}100 \\
\mathrm{pg} / \mathrm{mg}\end{array}$ \\
\hline PCB 101 & SPME-GC-NCI-MS/MS & $\gamma$-HCH-D 6 & 0.963 & 20 & 112 & N.D. & N.D. & N.D. & 104 & 13 & N.D. & N.D. & N.D. & 11 & N.D. & N.D. & 132 \\
\hline PCB 138 & SPME-GC-NCI-MS/MS & $\gamma$-HCH-D 6 & 0.984 & 10 & 116 & N.D. & N.D. & 116 & 103 & 6 & N.D. & N.D. & 6 & 10 & N.D. & 116 & 131 \\
\hline PCB 153 & SPME-GC-NCI-MS/MS & $\beta$-endosulfan- $\mathrm{D}_{4}$ & 0.955 & 20 & 100 & N.D. & N.D. & 157 & 99 & 22 & N.D. & N.D. & 18 & 12 & N.D. & 106 & 127 \\
\hline PCB 180 & $\begin{array}{l}\text { Liquid } \\
\text { Injection-GC-NCI-MS/MS }\end{array}$ & Permethrin- $\mathrm{D}_{6}$ & 0.995 & $0.3^{*}$ & N.A. & $102^{* * *}$ & $88^{* *}$ & $101^{* *}$ & 101 & 11 & 16 & 14 & 4 & 7 & 116 & 155 & 104 \\
\hline BDEs $28+33$ & SPME-GC-NCI-MS/MS & $\gamma$-HCH-D 6 & 0.990 & 20 & 79 & N.D. & N.D. & 68 & 97 & 8 & N.D. & N.D. & 15 & 7 & N.D. & 109 & 120 \\
\hline BDE 47 & $\begin{array}{l}\text { Liquid } \\
\text { Injection-GC-NCI-MS/MS }\end{array}$ & Permethrin- $\mathrm{D}_{6}$ & 0.990 & 5 & 90 & N.D. & N.D. & 79 & 101 & 20 & N.D. & N.D. & 5 & 9 & N.D. & 117 & 134 \\
\hline BDE 99 & $\begin{array}{l}\text { Liquid } \\
\text { Injection-GC-NCI-MS/MS }\end{array}$ & Permethrin- $\mathrm{D}_{6}$ & 0.988 & 5 & 95 & N.D. & N.D. & 10 & 100 & 19 & N.D. & N.D. & 11 & 8 & N.D. & 141 & 92 \\
\hline BDE 100 & $\begin{array}{l}\text { Liquid } \\
\text { Injection-GC-NCI-MS/MS }\end{array}$ & Permethrin- $\mathrm{D}_{6}$ & 0.991 & 2 & 96 & N.D. & N.D. & 105 & 99 & 22 & N.D. & N.D. & 15 & 6 & N.D. & 136 & 117 \\
\hline BDE 153 & $\begin{array}{l}\text { Liquid } \\
\text { Injection-GC-NCI-MS/MS }\end{array}$ & Permethrin- $\mathrm{D}_{6}$ & 0.990 & 5 & 94 & N.D. & N.D. & 108 & 102 & 13 & N.D. & N.D. & 9 & 6 & N.D. & 134 & 87 \\
\hline BDE 154 & $\begin{array}{l}\text { Liquid } \\
\text { Injection-GC-NCI-MS/MS }\end{array}$ & Permethrin- $\mathrm{D}_{6}$ & 0.986 & 5 & 114 & N.D. & N.D. & 96 & 101 & 12 & N.D. & N.D. & 16 & 6 & N.D. & 150 & 98 \\
\hline Bisphenol A & $\begin{array}{l}\text { Liquid } \\
\text { Injection-GC-NCI-MS/MS }\end{array}$ & BPA-d ${ }_{16}$ & 0.879 & 50 & 112 & N.D. & N.D. & N.D. & 106 & 16 & N.D. & N.D. & N.D. & 8 & N.D. & N.D. & 15 \\
\hline Bisphenol S & LC-MS/MS & Thiabendazole $-{ }^{13} \mathrm{C}_{6}$ & 0.964 & $9 *$ & N.A. & 1444 & 109 & 92 & 103 & 5 & 7 & 15 & 6 & 11 & 109 & 109 & 120 \\
\hline
\end{tabular}

ISTD, internal standard; LOQ, limit of quantification.
$*$ LOQ determined from concentrations in blank hair.

* $\mathrm{LOQ}$ determined from concent
N.A., Accuracy Not Applicable.

** Accuracy of level supplemented (i.e. determined concentration minus background concentration in blank hair).

N.D., not determined. 
Table S4 Concentrations (pg/mg) of PCBs, BDEs, BPA and BPS in human hair collected from the Chinese women in Baoding and Dalian and the French women in northeast and southwest.

\begin{tabular}{|c|c|c|c|c|c|c|c|c|c|c|c|c|c|c|c|c|c|c|}
\hline \multirow{2}{*}{ Analytes } & \multicolumn{8}{|c|}{ Baoding (n=102) } & \multicolumn{8}{|c|}{ Dalian $(n=102)$} & \multirow[t]{2}{*}{$p$-value } & \multirow[t]{2}{*}{ LOD } \\
\hline & DF (\%) & Mean & Min & $25 \% \mathrm{P}$ & $50 \% \mathrm{P}$ & $75 \% \mathrm{P}$ & $95 \% \mathrm{P}$ & Max & $\mathrm{DF}(\%)$ & Mean & Min & $25 \% \mathrm{P}$ & $50 \% \mathrm{P}$ & $75 \% \mathrm{P}$ & $95 \% \mathrm{P}$ & Max & & \\
\hline PCB101 & 0 & $<\mathrm{LOD}$ & $<\mathrm{LOD}$ & $<\mathrm{LOD}$ & $<\mathrm{LOD}$ & $<\mathrm{LOD}$ & $<\mathrm{LOD}$ & $<\mathrm{LOD}$ & 2 & 0.95 & $<\mathrm{LOD}$ & $<\mathrm{LOD}$ & $<\mathrm{LOD}$ & $<\mathrm{LOD}$ & $<\mathrm{LOD}$ & 63.2 & 0.156 & 0.26 \\
\hline PCB138 & 0 & $<$ LOD & $<$ LOD & $<$ LOD & $<$ LOD & $<$ LOD & $<$ LOD & $<$ LOD & 0 & $<$ LOD & $<\mathrm{LOD}$ & $<$ LOD & $<$ LOD & $<$ LOD & $<$ LOD & $<$ LOD & 1 & 0.03 \\
\hline PCB153 & 0 & $<\mathrm{LOD}$ & $<\mathrm{LOD}$ & $<\mathrm{LOD}$ & $<$ LOD & $<\mathrm{LOD}$ & $<\mathrm{LOD}$ & $<\mathrm{LOD}$ & 0 & $<\mathrm{LOD}$ & $<\mathrm{LOD}$ & $<$ LOD & $<\mathrm{LOD}$ & $<$ LOD & $<$ LOD & $<\mathrm{LOD}$ & 1 & 0.08 \\
\hline PCB180 & 49 & 0.16 & $<$ LOD & $<$ LOD & $<$ LOD & 0.15 & 0.89 & 2.12 & 39 & 0.06 & $<$ LOD & $<$ LOD & $<\mathrm{LOD}$ & 0.07 & 0.26 & 1.03 & 0.021 & 0.02 \\
\hline BDEs28_33 & 0 & $<\mathrm{LOD}$ & $<$ LOD & $<\mathrm{LOD}$ & $<$ LOD & $<$ LOD & $<\mathrm{LOD}$ & $<\mathrm{LOD}$ & 0 & $<\mathrm{LOD}$ & $<$ LOD & $<$ LOD & $<\mathrm{LOD}$ & $<$ LOD & $<$ LOD & $<$ LOD & 1 & 0.04 \\
\hline BDE47 & 12 & 0.2 & $<$ LOD & $<$ LOD & $<$ LOD & $<$ LOD & 0.55 & 4.99 & 10 & 0.23 & $<$ LOD & $<$ LOD & $<$ LOD & $<$ LOD & 0.9 & 7.87 & 0.684 & 0.15 \\
\hline BDE99 & 2 & $<\mathrm{LOD}$ & $<\mathrm{LOD}$ & $<\mathrm{LOD}$ & $<$ LOD & $<$ LOD & $<\mathrm{LOD}$ & 1.24 & 2 & $<$ LOD & $<$ LOD & $<$ LOD & $<\mathrm{LOD}$ & $<\mathrm{LOD}$ & $<$ LOD & 14.8 & 0.992 & 0.63 \\
\hline BDE100 & 2 & $<$ LOD & $<$ LOD & $<$ LOD & $<$ LOD & $<$ LOD & $<$ LOD & 0.83 & 2 & $<$ LOD & $<$ LOD & $<\mathrm{LOD}$ & $<$ LOD & $<$ LOD & $<\mathrm{LOD}$ & 9.49 & 1 & 0.23 \\
\hline BDE153 & 1 & $<$ LOD & $<$ LOD & $<$ LOD & $<$ LOD & $<$ LOD & $<$ LOD & 1.2 & 1 & $<$ LOD & $<$ LOD & $<$ LOD & $<$ LOD & $<$ LOD & $<$ LOD & 4.75 & 0.994 & 0.91 \\
\hline BDE154 & 0 & $<\mathrm{LOD}$ & $<$ LOD & $<$ LOD & $<$ LOD & $<$ LOD & $<$ LOD & $<$ LOD & 1 & $<\mathrm{LOD}$ & $<$ LOD & $<$ LOD & $<\mathrm{LOD}$ & $<$ LOD & $<$ LOD & 1.61 & 0.317 & 0.67 \\
\hline BPA & 100 & 60.6 & 7.85 & 25.6 & 38.1 & 64.8 & 160 & 544 & 100 & 47.1 & 5.47 & 21.8 & 30.8 & 53.2 & 123 & 596 & 0.029 & 5.47 \\
\hline BPS & 100 & 5.84 & 0.48 & 1.33 & 2.05 & 5.85 & 14.7 & 202 & 100 & 18.9 & 0.64 & 1.84 & 3.51 & 8.22 & 58.8 & 817 & 0.006 & 0.07 \\
\hline \multirow{2}{*}{ Analytes } & \multicolumn{8}{|c|}{ Northeast $(\mathrm{n}=182)$} & \multicolumn{8}{|c|}{ Southwest $(\mathrm{n}=129)$} & \multirow{2}{*}{\multicolumn{2}{|c|}{$p$-value }} \\
\hline & $\mathrm{DF}(\%)$ & Mean & Min & $25 \% \mathrm{P}$ & $50 \% \mathrm{P}$ & $75 \% \mathrm{P}$ & $95 \% \mathrm{P}$ & Max & $\mathrm{DF}(\%)$ & Mean & Min & $25 \% \mathrm{P}$ & $50 \% \mathrm{P}$ & $75 \% \mathrm{P}$ & $95 \% \mathrm{P}$ & Max & & \\
\hline PCB101 & 3 & $<$ LOD & $<$ LOD & $<$ LOD & $<$ LOD & $<$ LOD & $<$ LOD & 1.12 & 0 & $<$ LOD & $<$ LOD & $<$ LOD & $<$ LOD & $<$ LOD & $<$ LOD & $<$ LOD & 0.058 & \\
\hline PCB138 & 44 & 0.22 & $<\mathrm{LOD}$ & $<\mathrm{LOD}$ & $<\mathrm{LOD}$ & 0.3 & 0.94 & 2.44 & 47 & 0.21 & $<\mathrm{LOD}$ & $<\mathrm{LOD}$ & $<\mathrm{LOD}$ & 0.25 & 0.75 & 3.36 & 0.932 & \\
\hline PCB153 & 48 & 0.27 & $<$ LOD & $<$ LOD & $<$ LOD & 0.31 & 0.88 & 9.68 & 53 & 0.21 & $<$ LOD & $<$ LOD & 0.11 & 0.27 & 0.6 & 3.41 & 0.979 & \\
\hline PCB 180 & 80 & 0.33 & $<$ LOD & 0.1 & 0.23 & 0.42 & 1.04 & 2 & 84 & 0.42 & $<$ LOD & 0.11 & 0.27 & 0.49 & 1.16 & 6.79 & 0.226 & \\
\hline BDEs28_33 & 2 & $<$ LOD & $<$ LOD & $<$ LOD & $<$ LOD & $<$ LOD & $<$ LOD & 0.13 & 15 & 0.12 & $<$ LOD & $<$ LOD & $<\mathrm{LOD}$ & $<$ LOD & 0.66 & 3.37 & $2.30 \mathrm{E}-05$ & \\
\hline BDE47 & 56 & 4.34 & $<\mathrm{LOD}$ & $<\mathrm{LOD}$ & 1.1 & 4.36 & 19.3 & 82.1 & 59 & 9.15 & $<\mathrm{LOD}$ & $<$ LOD & 1.73 & 8.09 & 49.4 & 152 & 0.081 & \\
\hline BDE99 & 49 & 3.15 & $<$ LOD & $<$ LOD & $<$ LOD & 3.07 & 12.7 & 64.8 & 49 & 17.2 & $<$ LOD & $<$ LOD & $<\mathrm{LOD}$ & 4.38 & 109 & 396 & 0.389 & \\
\hline BDE100 & 15 & 0.53 & $<$ LOD & $<$ LOD & $<$ LOD & $<$ LOD & 2.37 & 24.2 & 26 & 2.13 & $<$ LOD & $<\mathrm{LOD}$ & $<\mathrm{LOD}$ & 0.72 & 11.4 & 73.7 & 0.01 & \\
\hline BDE153 & 1 & 0.49 & $<$ LOD & $<$ LOD & $<$ LOD & $<$ LOD & $<$ LOD & 6.89 & 11 & 4.48 & $<$ LOD & $<$ LOD & $<$ LOD & $<$ LOD & 21.7 & 234 & $1.10 \mathrm{E}-04$ & \\
\hline BDE154 & 2 & 0.39 & $<$ LOD & $<$ LOD & $<\mathrm{LOD}$ & $<$ LOD & $<\mathrm{LOD}$ & 8.17 & 7 & 2.55 & $<\mathrm{LOD}$ & $<$ LOD & $<\mathrm{LOD}$ & $<$ LOD & 9.49 & 112 & 0.015 & \\
\hline BPA & 100 & 184 & 20.6 & 63.5 & 117.5 & 223 & 540 & 1242 & 100 & 185 & 17.1 & 63.5 & 120 & 203 & 570 & 1398 & 0.901 & \\
\hline BPS & 100 & 64.5 & 0.08 & 2.03 & 7.44 & 29.5 & 401 & 1246 & 100 & 29.4 & 0.07 & 2.14 & 8.94 & 25.6 & 147 & 365 & 0.853 & \\
\hline
\end{tabular}

DF: detection frequency; LOD: limit of detection; Min: minimum; Max: maximum; $p$-values were obtained from Mann-Whitney U-test. 
Table S5 Multiple linear regression models of dominant chemicals on population characteristics.

\begin{tabular}{|c|c|c|c|c|c|}
\hline Country & Response & Explanatory variable & Coefficient & $95 \% \mathrm{CI}$ & $P$ \\
\hline \multirow{2}{*}{ China } & $\log 10 \mathrm{BPA}$ & - & - & - & - \\
\hline & Log10 BPS & Living in Dalian (vs. Baoding) & 0.209 & $(0.003,0.345)$ & $<0.001$ \\
\hline \multirow{6}{*}{ France } & \multirow{2}{*}{$\begin{array}{l}\log 10 \\
\text { PCB180 }\end{array}$} & Age (years) & 0.015 & $(0.000,0.030)$ & 0.045 \\
\hline & & University (vs. High school or less) & -0.207 & $(-0.355,-0.059)$ & 0.006 \\
\hline & \multirow{2}{*}{$\log 10 \mathrm{BPA}$} & $\mathrm{BMI}\left(\mathrm{kg} / \mathrm{m}^{2}\right)$ & 0.015 & $(0.007,0.024)$ & $<0.001$ \\
\hline & & University (vs. High school or less) & -0.142 & $(-0.222,-0.061)$ & $<0.001$ \\
\hline & \multirow{2}{*}{ Log10 BPS } & $\operatorname{BMI}\left(\mathrm{kg} / \mathrm{m}^{2}\right)$ & 0.021 & $(0.001,0.040)$ & 0.036 \\
\hline & & Smoking (vs. not) & 0.240 & $(0.037,0.443)$ & 0.021 \\
\hline
\end{tabular}

BPA in the hair of Chinese women was not significantly associated with any of population characteristics evaluated; Consumption frequency of fish/seafood or fish was not retained in any final models and is thus not shown in the table. 
Table S6 Comparison of concentrations of target compounds in human hair from various countries.

\begin{tabular}{|c|c|c|c|c|c|c|c|c|c|c|c|c|c|c|c|c|}
\hline Country & Survey year & Age & $\mathrm{N}$ & PCB101 & PCB 138 & РСB 153 & РСB 180 & BDE 28 & BDE 47 & BDE 99 & BDE 100 & BDE 153 & BDE 154 & BPA & BPS & References \\
\hline Canada & $\mathrm{NA}$ & $20-65$ & 50 & & & & & nd-22.6 & $4.6-815(21)$ & $5.8-1128(20.3)$ & nd-207 & nd-113.5 & nd-85.4 & & & Poon et al. (2014) \\
\hline Canada & $\mathrm{NA}$ & Female adults & 65 & & & & & nd-19.4 (nd) & nd-207.9 & nd-139.4 (6.9) & nd-23.3 (nd) & $\mathrm{nd}-15.7$ (nd) & nd-10.1 (nd) & & & Carnevale et al. (2014) \\
\hline Canada & $\mathrm{NA}$ & $1-15$ & 12 & & & & & nd-0.09 (nd) & $0.07-0.84$ & $0.04-1.18$ & nd -0.45 & nd- $-0.16(0.03)$ & nd-0.12 (nd) & & & Aleksa et al. (2012) \\
\hline USA & 2014 & $19-38$ & 50 & & & & & $0.23-8.6(1.0)$ & $5.2-880(33)$ & $2.2-1020(21)$ & $0.48-176$ & $1.4-78(2.4)$ & $0.16-54(1.2)$ & & & Liu et al. (2016) \\
\hline Germany & $\mathrm{NA}$ & Adults & 4 & & & & & & & & & & & $<41$ & & Martín et al. (2015) \\
\hline Greece & $2015-2016$ & $2-12$ & 50 & & & & & & & & & & & nd-205.5 (12.4) & & Karzi et al. (2018) \\
\hline Greece & 2015-2016 & $25-91$ & 72 & & & & & & & & & & & nd-53.8 (13.8) & & Karzi et al. (2018) \\
\hline Greece & 2011-2014 & Adults & 8 & & & & & & & & & & & 27.7 & & Tzatzarakis et al. (2015) \\
\hline Greece & 2011-2014 & Children & 61 & & & & & & & & & & & 45.6 & & Tzatzarakis et al. (2015) \\
\hline Poland & 2012 & $25-30$ & 12 & & & & & & nd-0.65 (0.4) & nd-0.42 (0.21) & nd & nd & nd & & & Król et al. (2014) \\
\hline Poland & $\mathrm{NA}$ & $16-55$ & 42 & & & & & & & & & & & 26.1-1498.6 & & Nehring et al. (2017) \\
\hline Romania & 2002-2003 & Adolescents & 42 & & $0.2-7.3(0.9)$ & $0.2-20.5(2.1)$ & & & & & & & & & & Covaci et al. (2008) \\
\hline Spain & $\mathrm{NA}$ & $\mathrm{NA}$ & 6 & & & & & & & & & & & nd-158 (44.5) & & Martín et al. (2016) \\
\hline Spain & $\mathrm{NA}$ & 24.44 & 9 & & & & & nd & $0.31-3.9(0.6)$ & $0.3-2.1(0.85)$ & $0.3-1.63(0.5)$ & nd & nd & & & Tadeo et al. (2009) \\
\hline Spain & $\mathrm{NA}$ & $1-11$ & 7 & & & & & nd & $0.31-0.69$ & $0.33-1.22(0.8)$ & $0.3-0.58$ & nd & nd & & & Tadeo et al. (2009) \\
\hline Spain & $\mathrm{NA}$ & $>18$ & 6 & & & & & & & & & & & nd-45 (4.6) & & Rodríguez-Gómez et al. (2017) \\
\hline Iran & $2007-2008$ & $18-36$ & 21 & $\mathrm{nd}-2.5$ (nd) & nd- $-4.5(0.4)$ & nd-4(nd) & nd-138 (6.5) & & & & & & & & & Behrooz et al. (2012) \\
\hline Iran & 2007-2008 & $16-43$ & 16 & nd- -1.0 (nd) & nd- $-0.6(0.3)$ & nd & $3.5-13.5(7)$ & & & & & & & & & Behrooz et al. (2012) \\
\hline Iran & 2007-2008 & $15-36$ & 19 & nd & nd-1. $1.0(0.4)$ & nd & nd-15 (nd) & & & & & & & & & Behrooz et al. (2012) \\
\hline Korea & $\mathrm{NA}$ & $25-28$ & 10 & & & & & & & & & & & $17.0-22.9$ & & Lee et al. (2017) \\
\hline Philippines & 2008 & $18-36$ & 10 & $0.55-3.6(1.7)$ & $0.91-7.3(3.7)$ & $0.70-8.0(3.8)$ & $0.91-5.9$ & $0.11-0.46$ & $1.8-28(3.4)$ & $0.73-6.7(1.0)$ & $<0.02-0.86$ & $0.25-4.5$ & $0.10-0.71$ & & & Malarvannan et al. (2013) \\
\hline China (Guangdong) & $\mathrm{NA}$ & $22-42$ & 18 & & & & & nd & $0.86-5.24$ & $0.22-1.47$ & $0.13-0.49$ & nd & nd & & & Kang et al. (2011) \\
\hline
\end{tabular}




\begin{tabular}{|c|c|c|c|c|c|c|c|c|c|c|c|c|c|c|c|c|}
\hline China (Guangdong) & 2014 & $21-25$ & 43 & & & & & $(0.02)$ & (nd) & (nd) & (nd) & $(0.06)$ & (nd) & & & Qiao et al. (2018) \\
\hline China (Guangdong) & $\mathrm{NA}$ & $\mathrm{NA}$ & 29 & & & & & & $0.13-5.27$ & $0.07-2.62$ & nd- -0.76 & nd-0.82 (0.08) & nd- -0.22 & & & Zheng et al. (2011) \\
\hline China (Guangdong) & $\mathrm{NA}$ & $\mathrm{NA}$ & 32 & & & & & & $0.09-2.42$ & $0.09-1.17$ & $0.03-0.20$ & $0.03-0.51$ & nd- -0.11 & & & Zheng et al. (2011) \\
\hline China (Shanghai) & 2010 & Male adults & 14 & & & & & $0.13-0.81$ & $0.05-2.17$ & $0.03-2.51$ & nd-0.45 (nd) & nd-0.27 (0.03) & nd-0. 17 (nd) & & & Tang et al. (2013) \\
\hline China (Shanghai) & 2010 & Female adults & 11 & & & & & $0.26-3.43$ & $0.14-1.68$ & nd- $-0.87(0.26)$ & nd & nd- $0.46(0.2)$ & nd- -0.23 (nd) & & & Tang et al. (2013) \\
\hline China (Shanghai) & 2007 & $18-50$ & 11 & & & & & $0.42-3.66$ & $2.70-32.6$ & $0.3-13.1$ & $0.12-2.62$ & nd-1.113 & nd- -0.71 & & & Ma et al. (2011) \\
\hline China (Zhejiang) & 2015 & 23-62 & 65 & & & & & nd-20.8 & nd-1.1.9 & nd- 6.8 & nd- 0.5 & nd-3.0 & nd- 0.4 & & & Liang et al. (2016) \\
\hline China (Zhejiang) & 2015 & 24.57 & 22 & & & & & nd-1..3 & nd-9.5 & nd-3.3.7 & nd-1. 1.8 & nd-6.6 & nd-3.9 & & & Liang et al. (2016) \\
\hline China (Zhejiang) & 2007 & Adults & 4 & $0.47-1.79$ & $0.87-3.26$ & $0.13-0.44$ & $0.10-0.47$ & $0.53-1.14$ & $1.07-1.57$ & $0.25-0.45$ & $0.25-1.81$ & $0.30-1.39$ & nd & & & Zhao et al. (2008) \\
\hline China (Zhejiang) & 2005 & Female adults & 5 & & & & & nd- -0.42 & nd-1.07 (0.34) & nd-0.44 (0.15) & nd- 0.12 & nd-0.41 (0.04) & nd- -0.10 & & & Leung et al. (2010) \\
\hline China & 2016 & $25-45$ & 204 & nd-20.4 (nd) & nd & nd & nd-2.12 (nd) & $\mathrm{nd}^{\circ}$ & nd-7.87 (nd) & nd-14.8 (nd) & nd-9.99 (nd) & nd-4.75 (nd) & nd-1.61 (nd) & $5.47-596(34.9)$ & $0.48-817$ & This study \\
\hline France & 2011 & $18-43$ & 311 & nd-1.12 (nd) & $\mathrm{nd}-3.36$ (nd) & nd-9. .68 (nd) & nd- 6.79 & nd-3.37 (nd) & nd-152 (1.37) & nd-396 (nd) & nd-73.7 (nd) & nd-234 (nd) & nd-112 (nd) & $17.0-1398$ (118) & $0.10-1246$ & This study \\
\hline
\end{tabular}

(B) 28 represents BDE 28 and 33 (BDE 28 +33$)$.

We did not include data on occupational exposures or residence around e-waste recycling area or plants. 


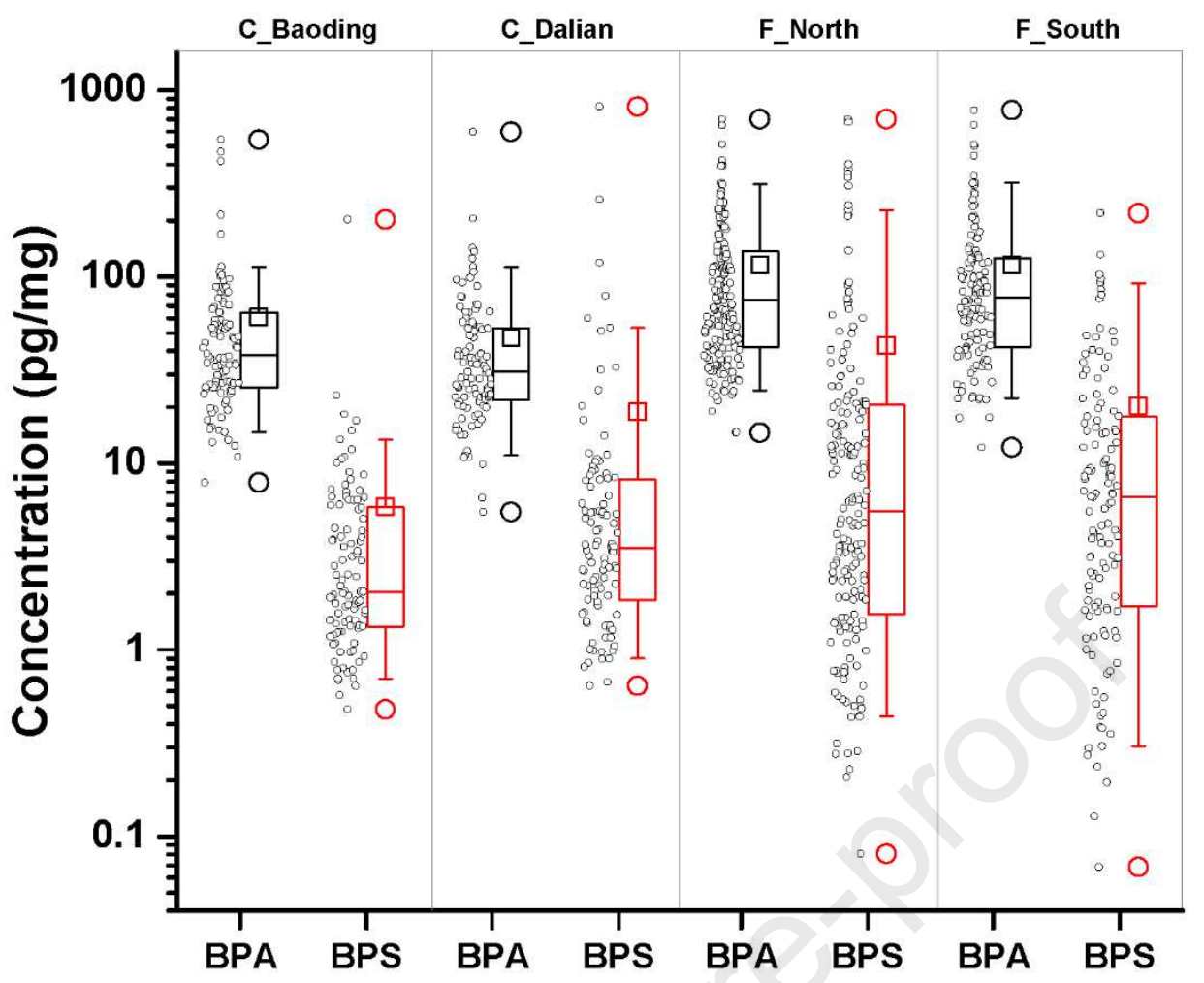

Fig. S1. Concentrations of BPA and BPS in hair samples collected from the Chinese women in Baoding $(n=102)$, the Chinese women in Dalian $(n=102)$, the French women in northeast $(n=182)$, and the French women in southwest $(n=129)$. Black circles indicate hair samples. Boxes represent 25-75 percentiles, with whiskers of $5^{\text {th }}$ and $95^{\text {th }}$ percentiles. The lowest and highest circles indicate the minimum and maximum. Lines inside the boxes represent medians while squares represent means. 


\section{References}

Aleksa, K.; Carnevale, A.; Goodyer, C.; Koren, G. Detection of polybrominated biphenyl ethers (PBDEs) in pediatric hair as a tool for determining in utero exposure. Forensic Science International 2012;218:37-43

Behrooz, D.R.; Barghi, M.; Bahramifar, N.; Esmaili-Sari, A. Organochlorine contaminants in the hair of Iranian pregnant women. Chemosphere 2012;86:235-241

Carnevale, A.; Aleksa, K.; Goodyer, C.G.; Koren, G. Investigating the Use of Hair to Assess Polybrominated Diphenyl Ether Exposure Retrospectively. Therapeutic Drug Monitoring 2014;36:244-251

Chen, D.; Kannan, K.; Tan, H.L.; Zheng, Z.G.; Feng, Y.L.; Wu, Y.; Widelka, M. Bisphenol Analogues Other Than BPA: Environmental Occurrence, Human Exposure, and Toxicity-A Review. Environmental Science \& Technology 2016;50:5438-5453

Covaci, A.; Hura, C.; Gheorghe, A.; Neels, H.; Dirtu, A.C. Organochlorine contaminants in hair of adolescents from Iassy, Romania. Chemosphere 2008;72:16-20

Kang, Y.; Wang, H.S.; Cheung, K.C.; Wong, M.H. Polybrominated diphenyl ethers (PBDEs) in indoor dust and human hair. Atmospheric Environment 2011;45:2386-2393

Karzi, V.; Tzatzarakis, M.N.; Vakonaki, E.; Alegakis, T.; Katsikantami, I.; Sifakis, S.; Rizos, A.; Tsatsakis, A.M. Biomonitoring of bisphenol A, triclosan and perfluorooctanoic acid in hair samples of children and adults. 2018;38:1144-1152

Król, S.; Namieśnik, J.; Zabiegała, B. Occurrence and levels of polybrominated diphenyl ethers (PBDEs) in house dust and hair samples from Northern Poland; an assessment of human exposure. Chemosphere 2014;110:91-96

Lee, C.; Kim, C.H.; Kim, S.; Cho, S.-H. Simultaneous determination of bisphenol A and estrogens in hair samples by liquid chromatography-electrospray tandem mass spectrometry. Journal of Chromatography B 2017;1058:8-13

Leung, A.O.W.; Chan, J.K.Y.; Xing, G.H.; Xu, Y.; Wu, S.C.; Wong, C.K.C.; Leung, C.K.M.; Wong, M.H. Body burdens of polybrominated diphenyl ethers in childbearing-aged women at an intensive electronic-waste recycling site in China. Environmental Science and Pollution Research 2010; $17: 1300-1313$

Liang, S.; Xu, F.; Tang, W.; Zhang, Z.; Zhang, W.; Liu, L.; Wang, J.; Lin, K. Brominated flame retardants in the hair and serum samples from an e-waste recycling area in southeastern China: the possibility of using hair for biomonitoring. Environmental Science and Pollution Research 2016;23:14889-14897

Liu, L.Y.; He, K.; Hites, R.A.; Salamova, A. Hair and Nails as Noninvasive Biomarkers of Human Exposure to Brominated and Organophosphate Flame Retardants. Environmental Science \& Technology 2016;50:3065-3073

Llorca-Porcel, J.; Martínez-Sánchez, G.; Álvarez, B.; Cobollo, M.A.; Valor, I. Analysis of nine polybrominated diphenyl ethers in water samples by means of stir bar sorptive extraction-thermal desorption-gas chromatography-mass spectrometry. Analytica Chimica Acta 2006;569:113-118

Ma, J.; Cheng, J.; Wang, W.; Kunisue, T.; Wu, M.; Kannan, K. Elevated concentrations of polychlorinated dibenzo-p-dioxins and polychlorinated dibenzofurans and polybrominated diphenyl ethers in hair from workers at an electronic waste recycling facility in Eastern China. Journal of Hazardous Materials 2011;186:1966-1971

Malarvannan, G.; Isobe, T.; Covaci, A.; Prudente, M.; Tanabe, S. Accumulation of brominated flame retardants and polychlorinated biphenyls in human breast milk and scalp hair from the Philippines: Levels, distribution and profiles. Science of The Total Environment 2013;442:366-379

Martín, J.; Möder, M.; Gaudl, A.; Alonso, E.; Reemtsma, T. Multi-class method for biomonitoring of hair samples using gas chromatography-mass spectrometry. Analytical and Bioanalytical Chemistry 2015;407:8725-8734

Martín, J.; Santos, J.L.; Aparicio, I.; Alonso, E. Analytical method for biomonitoring of endocrine-disrupting compounds (bisphenol A, parabens, perfluoroalkyl compounds and a brominated flame retardant) in human hair by liquid chromatography-tandem mass spectrometry. Analytica Chimica Acta 2016;945:95-101

Michałowicz, J. Bisphenol A - Sources, toxicity and biotransformation. Environmental Toxicology and Pharmacology 2014;37:738-758

Nehring, I.; Staniszewska, M.; Falkowska, L. Human Hair, Baltic Grey Seal (Halichoerus grypus) Fur and Herring Gull (Larus argentatus) Feathers as Accumulators of Bisphenol A and Alkylphenols. Archives of Environmental Contamination and Toxicology 2017;72:552-561

Norström, K.; Czub, G.; McLachlan, M.S.; Hu, D.; Thorne, P.S.; Hornbuckle, K.C. External exposure 
and bioaccumulation of PCBs in humans living in a contaminated urban environment. Environment International 2010;36:855-861

Poon, S.; Wade, M.G.; Aleksa, K.; Rawn, D.F.K.; Carnevale, A.; Gaertner, D.W.; Sadler, A.; Breton, F.; Koren, G.; Ernest, S.R.; Lalancette, C.; Robaire, B.; Hales, B.F.; Goodyer, C.G. Hair as a Biomarker of Systemic Exposure to Polybrominated Diphenyl Ethers. Environmental Science \& Technology 2014;48:14650-14658

Qiao, L.; Zheng, X.-B.; Yan, X.; Wang, M.-H.; Zheng, J.; Chen, S.-J.; Yang, Z.-Y.; Mai, B.-X. Brominated flame retardant (BFRs) and Dechlorane Plus (DP) in paired human serum and segmented hair. Ecotoxicology and Environmental Safety 2018;147:803-808

Rodríguez-Gómez, R.; Martín, J.; Zafra-Gómez, A.; Alonso, E.; Vílchez, J.L.; Navalón, A. Biomonitoring of 21 endocrine disrupting chemicals in human hair samples using ultra-high performance liquid chromatography-tandem mass spectrometry. Chemosphere 2017;168:676-684

Tadeo, J.L.; Sanchez-Brunete, C.; Miguel, E. Determination of polybrominated diphenyl ethers in human hair by gas chromatography-mass spectrometry. Talanta 2009;78:138-143

Tang, L.; Lei, B.; Xu, G.; Ma, J.; Lei, J.-Q.; Jin, S.-Q.; Hu, G.-Y.; Wu, M.-H. Polybrominated Diphenyl Ethers in Human Hair from the College Environment: Comparison with Indoor Dust. Bulletin of Environmental Contamination and Toxicology 2013;91:377-381

Tzatzarakis, M.N.; Vakonaki, E.; Kavvalakis, M.P.; Barmpas, M.; Kokkinakis, E.N.; Xenos, K.; Tsatsakis, A.M. Biomonitoring of bisphenol A in hair of Greek population. Chemosphere 2015;118:336-341

Veith, G.D.; DeFoe, D.L.; Bergstedt, B.V. Measuring and Estimating the Bioconcentration Factor of Chemicals in Fish. Journal of the Fisheries Research Board of Canada 1979;36:1040-1048

Zhao, G.; Wang, Z.; Dong, M.H.; Rao, K.; Luo, J.; Wang, D.; Zha, J.; Huang, S.; Xu, Y.; Ma, M. PBBs, PBDEs, and PCBs levels in hair of residents around e-waste disassembly sites in Zhejiang Province, China, and their potential sources. Science of The Total Environment 2008;397:46-57

Zheng, J.; Luo, X.-J.; Yuan, J.-G.; Wang, J.; Wang, Y.-T.; Chen, S.-J.; Mai, B.-X.; Yang, Z.-Y. Levels and sources of brominated flame retardants in human hair from urban, e-waste, and rural areas in South China. Environmental Pollution 2011;159:3706-3713 


\section{CRediT authorship contribution statement}

Feng-Jiao Peng: Formal analysis, Writing - original draft. Emilie M. Hardy: Investigation, Writing - review \& editing. Rémi Béranger: Methodology, Funding acquisition, Writing - review \& editing. Sakina Mezzache: Conceptualization, Project administration, Supervision, Writing review \& editing. Nasrine Bourokba: Conceptualization, Project administration, Supervision, Writing - review \& editing. Philippe Bastien: Formal analysis, Writing - review \& editing. Jing Li: Project administration, Writing - review \& editing. Cécile Zaros: Methodology, Funding acquisition, Writing - review \& editing. Cécile Chevrier: Methodology, Funding acquisition, Writing - review \& editing. Paul Palazzi: Investigation, Writing - review \& editing. Jeremie Soeur: Conceptualization, Project administration, Supervision, Writing - review \& editing. Brice M.R. Appenzeller: Supervision, Methodology, Resources, Funding acquisition, Writing - original draft. 